\title{
Three Decades of Poverty Mobility in Nigeria: The Trapped, the Freed, and the Never Trapped
}

\section{Zuhumnan Dapel}

\begin{abstract}
Individuals do escape poverty during periods of overall rise in the poverty rate; they also transit into poverty during periods of overall decline in the poverty rate. A static poverty estimate drawn from independent cross surveys tends to obscure these details because it is unable to provide information on individual poverty experiences across time and space. In this paper, I explore six sweeps of household surveys of Nigeria (1980-2010) in an attempt to address these concerns. In addition, I test, by estimating poverty regressions, whether different processes are at work in determining chronic and transient poverty.
\end{abstract}

Between 1980 and 1985, about 0.11-9.5 percent of Nigeria's population escaped poverty. At the same time, 21.94-32.27 percent moved into poverty. Both transient and chronic poverty were higher in 1996-2010 than in 1980-1992. But transient poverty rose faster as the share of chronic poverty declined to between 3-55 percent from about 90 percent. Chronic poverty is less prevalent in Nigeria's oil producing region and more prevalent in the country's northeast, and poverty increases with household size. About 81 percent of those trapped in poverty farm, and 81.02 percent are from the north. Years of schooling has the strongest negative impact on chronic poverty; 74 percent of those never trapped in poverty have more than a high school level of education. Stepping up girls' education can mitigate teenage pregnancies and consequently address population rise among the poor. In addition, increasing investment in human capital, through government spending, can help break the cycle of poverty in the north.

Keywords: poverty, chronic, transient, mobility, synthetic, panel, Nigeria

JEL: I31

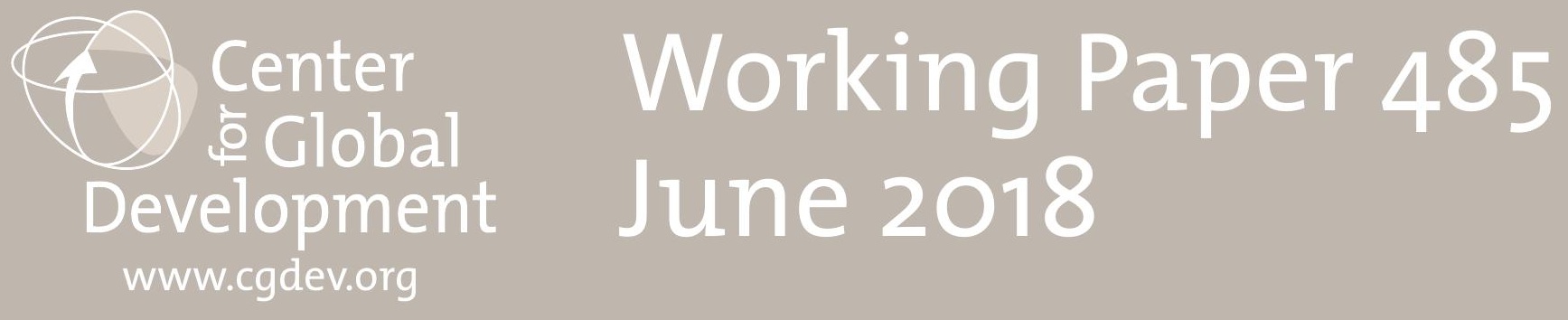




\title{
Three Decades of Poverty Mobility in Nigeria: The Trapped, the Freed, and the Never Trapped
}

\author{
Zuhumnan Dapel \\ Center for Global Development; University of Dundee, Scotland; and \\ Woodrow Wilson International Center for Scholars
}

I would like to thank Mead Over, Hai-Anh H. Dang, and Emily Schabacker for their helpful review, and the Scottish Institute for Research in Economics, Scotland UK for support of my research.

The Center for Global Development is grateful for contributions from the International Development Research Centre in support of this work.

Zuhumnan Dapel, 2018. "Three Decades of Poverty Mobility in Nigeria: The Trapped, the Freed, and the Never Trapped." CGD Working Paper 485. Washington, DC: Center for Global Development. https://www.cgdev.org/publication/three-decades-povertymobility-nigeria-trapped-freed-and-never-trapped

Center for Global Development 2055 L Street NW Washington, DC 20036

202.416 .4000

(f) 202.416 .4050

www.cgdev.org
The Center for Global Development is an independent, nonprofit policy research organization dedicated to reducing global poverty and inequality and to making globalization work for the poor. Use and dissemination of this Working Paper is encouraged; however, reproduced copies may not be used for commercial purposes. Further usage is permitted under the terms of the Creative Commons License.

The views expressed in CGD Working Papers are those of the authors and should not be attributed to the board of directors, funders of the Center for Global Development, or the authors' respective organizations. 


\section{Contents}

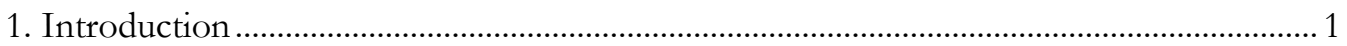

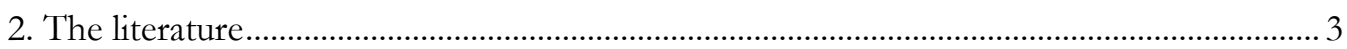

3. Methodology for measuring poverty dynamics ............................................................... 5

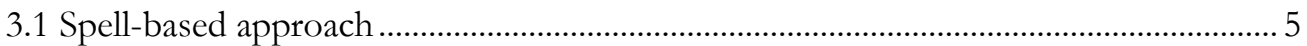

3.2 Component-based approach: measuring chronic and transient poverty ...................... 6

4. Estimating transient and chronic poverty models .............................................................10

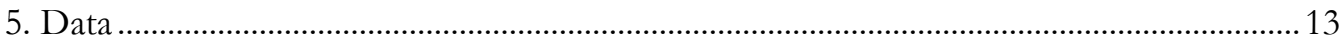

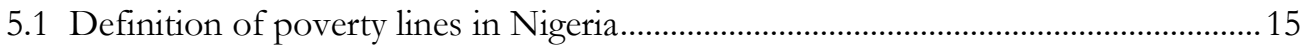

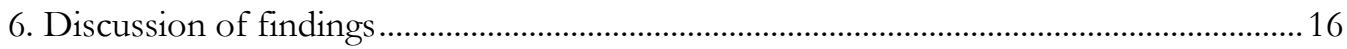

6.1 Results from component-based approach ………………………………………........ 19

6.2 Determinants of poverty entries and exits ..................................................................2

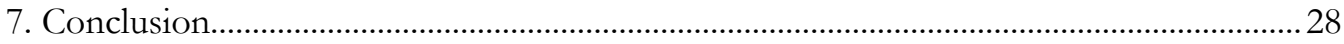

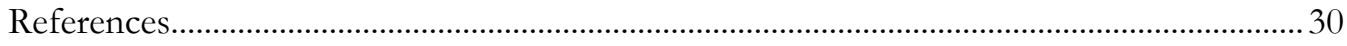

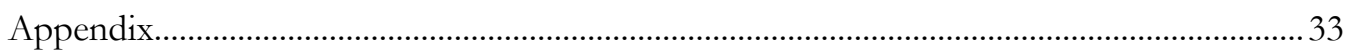

Meeting the data requirement: construction of synthetic panel......................................... 33

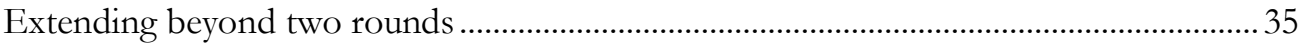


"Consider two countries in which half of the population is poor at each of two dates, but in one country it is the same households who are poor over time, while in the other it is none of the same households. Few observers will view these two extremes the same way. Yet that is what a conventional poverty measure such as the proportion of the population living below the poverty line at one time, does."

- Jalan and Ravallion (1998)

“...during the 1990s, Vietnam experienced a significant reduction in poverty: from 1993 to 1998 , rural and urban poverty rates fell by about $24 \%$ and $15 \%$ respectively. But these aggregate poverty trends tell us nothing about what happened to individual households."

- The 2004/05 Chronic Poverty Report on Vietnam

"In Uganda for instance the poverty headcount fell from 55.7\% of the population in 199292 to $34.2 \%$ in $1999-2000$ a decline of $20.4 \%$ points. But, an examination of those households that were in the panel between these two rounds, among whom the decline was $17.5 \%$, shows that between these years $29.2 \%$ of households moved out of poverty and $11.7 \%$ moved in-in other words there was substantial mobility"

- Appleton (2001)

\section{Introduction}

Individuals do escape poverty during periods of aggregate rise in the poverty rate; they also transit into poverty during periods of aggregate decline in the poverty rate. A static (or a point-in-time) poverty estimate, drawn from independent cross surveys, tends to obscure these essential details as it is unable to provide information on individual poverty experiences across time and across space. Using a static poverty profile, one cannot determine the fraction of the entire population that moved out of poverty, stayed in poverty, or moved into poverty, or the fraction that stayed out of poverty based on sample-specific dates.

As far as am aware, there are three known exhaustive studies on poverty mobility in Africa (see Dercon and Shapiro (2007) on Ethiopia, Dang and Dabalen (2018) on Sub-Saharan Africa and Woolard and Klasen (2005) on South Africa), but none on Nigeria. The paper is the first to carry out similar study on Nigeria. In this paper, I explore the available six sweeps of household surveys of Nigeria, spanning 1980-2010, in an attempt to address the above concerns. I estimate the rates of poverty transitions and the two components of poverty dynamics. In addition, I test whether different processes are at work in determining the estimated two components of poverty. I do so by estimating poverty regressions using a censored conditional quantile estimation method, a method considered to be robust in the 
presence of misspecifications in the error distribution. These exercises are essential in that maximizing progress against poverty requires understanding the type of poverty at issue and its determinants; different types of poverty will respond differently to particular policy interventions.

According to the official figures published by the National Bureau of Statistics (NBS) of Nigeria, the incidence of poverty in Nigeria between 1980 and 2010 rose from 27.2 percent to 69.0 percent. However, given that they were drawn from independent cross-section surveys, these figures (point-in-time estimates of poverty) do not tell us whether households are persistently poor and do not reveal if households typically transit into and/or out of poverty across time. The point-in-time estimation of poverty rate immensely underestimates the number of people who experience poverty over a period of two years or more. For example, an analysis of the first two years of the British Household Panel Survey-BHPS (1991-92) by Jarvis and Jenkins (1995), reveal that an average of 17 percent were poor at any one point in time but that, across the two years, 24 percent had experienced poverty at least once. In other words, there was much movement into and out of poverty over the period - a case of poverty spell repetition. Identifying and classifying households according to their poverty experiences are crucial, as the causes and policies needed to address these types of poverty are not congruent. For instance, using China rural household surveys, Jalan and Ravallion (1998) found that "the determinants of chronic and transient poverty are different, and therefore policies aimed at reducing chronic poverty may have little or no effect on transient poverty."

To gain a richer picture of individual household welfare over time, studies have moved beyond conventional poverty analysis (e.g., controlling for household demographics in a consumption regression, splitting poverty changes into growth and redistribution components, etc.) to look at variations in household welfare across poverty lines, time, and permanent income. This approach challenges the conventional view of "the poor" as a homogenous and essentially static population, and shows that for most people who experience it, poverty is not a fixed, unchanging status (see Walker and Park (1998), and Smith and Middleton (2007) for details). Poverty dynamics research has found that the number of people who experience poverty over a period is far greater than the number of poor at any one single moment in time. My focus is therefore the study of the poor defined as those who are poor at all dates (for which data is available) and those who move in and out of poverty. These moves are obvious regardless of how poverty is measured-in absolute or in relative terms.

This paper is organized as follows. In section 2, I examine the literature on poverty dynamics. In section 3, I present the paper's methodology on measuring poverty dynamics. In section 4, I estimate models of the different styles of poverty examined in section 3 using censored least absolute deviation (CLAD), the determinants of the two types of poverty. In section 5, I review the data, and a discussion of results in presented in section 6 . The conclusion appears in section 7 . To meet the data requirement for the exercises in sections 3 , I construct a synthetic panel, described in an appendix. 


\section{The literature}

Unlike a point-in-time (or snapshot) analysis of poverty, dynamic analysis of poverty reveals how people experience chronic and transient poverty across time and across space. As it traces the same individuals or households over time, it sheds light on the proportion of the entire population that (i) transits in and out of poverty; (ii) stays in poverty; and (iii) stays out of poverty.

There are two primary approaches in the literature to measuring and analysing poverty dynamics. The first is the spell-based method (Bane and Ellwood, 1986; Jarvis and Jenkins, 1995; Shaw, 1996; Jenkins, 2001; Cappellari and Jenkins, 2002; and Dang et al., 2014) and the second is the component-based method (Jalan and Ravallion, 1998; and Duclos et al., 2010). The spell-based method (SBM) focuses only on movement back and forth across the poverty line in income (or consumption) of households, because the SBM only looks at movement back and forth across the poverty line, it does not capture poverty dynamics evident in income variability that occurs only below the poverty line. This measure will deem as chronically poor those whose income (or consumption) in sample-specific dates falls below the poverty line and transiently poor those with income (or consumption) variability around the poverty line-poor, but not poor at all dates for which data is observed. For this measure, the degree of transiency (or the share of transient poverty) in total poverty will be zero for a given household if no oscillation in income (or consumption) of the household around the poverty line across households and over time is recorded (Morduch, 1994; and Dang et al., 2014).

Expanding on the basic concepts of the SBM, Hulme and Shephard (2003) provides a fourtier categorization of poverty experiences across time: (i) the always poor-those with income (or consumption) in each available observed period below a given poverty line; (ii) the usually poor - the longitudinal average of their living standards, over all observed periods, is below the defined poverty threshold, but non-poor in at least one of the periods; (iii) the churning poor - the living standards, over time, fluctuates around the poverty line; they stay out of poverty as much are they stay in; (iv) the occasionally poor-their time-mean (a surrogate of permanent income) is above the poverty line but they have, at least, experienced a poverty spell.

The SBM has been questioned on a number of grounds, including its measurement of transient poverty. For instance, Jalan and Ravallion (1998) do not identify transient poverty only based on movement across the poverty line as posited by the SBM. Instead, they define the transient poor as including people who are always poor, but whose consumption varies around their "time-mean" (or average of income streams, i.e., a surrogate of permanent income). Morduch (1994) referred to this stochastic poverty as it generates the presence of risk.

Another concerned raised by Bane and Ellwood (1984) is that the SBM disregards the duration of poverty spells, an aspect considered by Duncan (1984) to be integral to the dynamic analysis of poverty. To address this gap, Bane and Ellwood introduce spell durations and exit probabilities in their analysis of poverty dynamics. They define the 
poverty spell as beginning the first year an individual's income falls below the poverty line and ending when the income rises above the line. The exit probabilities are defined as the chances of an individual escaping poverty (i.e., ending a poverty spell) conditional on the duration spent below the poverty line. Although Bane and Ellwood use income as the welfare indicator variable in their analysis, they recognize that this variable is highly volatile, e.g., due to measurement error usually associated with most surveys in developing countries (Deaton, 1997). This may result in a false "spell," caused by a false beginning or end; a slight "random" change in income may move people in and out of poverty within a short span of time even though no significant changes in their incomes have taken place. To address this potential bias in identifying a spell, Bane and Ellwood exclude one-year spells from their sample; no spell lasting more than a year is excluded.

Stevens (1994), however, notes that eliminating one-year spells ignores the tendencies for people to experience repeated episodes of poverty, or multiple spells. She notes that, "one way to assess the importance of repeated spells of poverty is to examine the duration of subsequent non-poverty spells," that is, the likelihood of returning to poverty after escaping it, regardless of the duration that defined the spell. Corroborating this, Andriopoulou and Tsakloglou (2011) use the European Community Household Panel to show that "the probability of exiting poverty falls with previous experiences in poverty." At the same time, there is a high probability of those previously poor falling back into poverty as a decreasing function of years spent above the poverty line. In this setting, the longer-term poor have a low probability of exit and high probability of re-entry, which tend to reinforce each other. Furthermore, households experiencing shorter spells in poverty tend to be different from those of the longer-term poor. In the same vein, Stevens's results, obtained using the US Panel Study of Income Dynamics, revealed that "after one year out of poverty, 27 percent of those previously poor have started a new poverty spell. Of those that survive non-poor for a second year, 16 percent will fall back into poverty during the next year."

Applying this method to construct poverty spell and calculate exit probabilities over consecutive years requires longitudinal household surveys spanning several years (Andriopoulou and Tsakloglou, 2011). However, Nigeria lacks this data; its available household surveys are not only sporadic but repeated independent cross-sections (FOS, 1999 and NBS, 2012). Attempting to meet the data requirement for this exercise by following Deaton (1985) to construct a pseudo panel or Dang et al. (2014) to construct a synthetic panel does not resolve the problem: the irregularly spaced nature of the dataset remains a major limitation in calculating yearly exit probabilities, let alone estimating the associated hazard model using a logit specification. It is, therefore, beyond the scope of this paper to analyse the duration spell aspect of poverty dynamics.

The second approach in the literature to measuring and analysing poverty dynamics is the component-based method (CBM), which is discussed in detail in the methodology section of this paper. This approach decomposes total poverty into two components: transient and chronic. Jalan and Ravallion (1998) is an early and notable CBM study; in its wake, poverty dynamics have been analyzed for a wide range of countries, including Pakistan, Brazil, Argentina, and South Africa (Cruces and Wodon 2003). 
Recall that the spell-based approach understates the extent of transient poverty by ignoring variability in living standards below the poverty line. One advantage of the CBM method used by Jalan and Ravallion (here after JR) is that it addresses this short-coming by capturing variability in income streams, not just around the poverty line, but also around "permanent income" when the household is poor at all sample-specific dates. Specifically, JR note:

"An individual, we measure transient poverty by the contribution to expected poverty of the variability over time in the individual welfare indicator; if the indicator does not change then transient poverty is zero. We do not identify transient poverty as simply crossing the poverty line. However, this focus does mean that consumption fluctuations entirely above the poverty line are ignored."

However, the potential findings with the application of the JR's approach, as observed by Langeheine et al. (1998); Breen et al (2004) and Duclos et al. (2010), are very sensitive to the presence of measurement errors. To correct for these biases, Duclos et al. (2010) introduce measures that are deemed to be sensitive to ill-fare (or inequality among the poor) and the concerns arising from a relatively small number of periods (in our case $t=3$ ). In the sections that follow, I apply both approaches in analysing poverty dynamics in Nigeria. However, due to data limitation, I exclude from the analysis the calculation of poverty exit probabilities. I also proceed to model the determinants of total poverty, transient poverty, and chronic poverty based on JR using the appropriate estimators (details of this to follow in the methodology section).

\section{Methodology for measuring poverty dynamics}

Measuring poverty dynamics requires a panel dataset. For Nigeria, however, no such dataset exists. Below, I discuss how I overcome this limitation. Next, I measure poverty dynamics using spell-based and component-based techniques. The first approach focuses on transitions from one welfare status to another; the second focuses on estimating the transitory and permanent components of welfare.

\subsection{Spell-based approach}

What fraction of households in the population is below the poverty line in round 2 after being above the poverty line in round 1 ? That is, we are interested in estimating the degree of movement into poverty over two periods:

$$
p\left(y_{i 1}>z \text { and } y_{i 2}<z\right)
$$

Let $y_{i 1}$ and $y_{i 2}$ be respectively the first and second rounds consumptions (in real terms) of the $i$ th household and denote by $\mathbf{Z}$ (time-invariant) the real poverty line for the two rounds in question. Both survey rounds are random samples of the underlying population of interest, and each consists of a sample of $n_{1}$ and $n_{2}$ households correspondingly. In the spell-based approach, the following cases then are of interest: comparing $i$ th household's consumption $y_{i t}$ with poverty threshold $\boldsymbol{z}$ fixed in real terms, over two periods, $t=1,2$ : for 
transitions between two rounds, we are interested in estimating the fraction, from the entire population, of:

i. poor households in the first round of the survey who escaped poverty, i.e., mobility out of poverty:

$$
y_{i 1}<z \text { and } y_{i 2}>z
$$

ii. non-poor households in the first round of the survey who became poor, i.e., transition into poverty:

$$
y_{i 1}>z \text { and } y_{i 2}<z
$$

iii. poor households who remain poor in both rounds of the survey, poverty immobility, i.e., poor in the first round and remained poor in the second round:

$$
y_{i 1}<z \text { and } y_{i 2}<z
$$

iv. non-poor households in the first round who remained non-poor in the second round, poverty immobility i.e., non-poor and remain non-poor:

$$
y_{i 1}>z \text { and } y_{i 2}>z
$$

" $"$ " is either, " $\geq$ " or " $\leq$ "as relevant:

$$
p\left(y_{i 1} \sim z \text { and } y_{i 2} \sim z\right)
$$

\subsection{Component-based approach: measuring chronic and transient poverty}

In this section, we follow Jalan and Ravallion (1998) (here after JR) and Duclos et al. (2010) to estimate measures of transient and chronic poverty. According to JR, a chronically poor household is defined as one with time-mean consumption [over an observed sample period] below a given poverty line. The time-mean is defined as the average sample consumption over time. Specifically, consider $\left(y_{i 1}, y_{i 2}, \ldots, y_{i t}\right)$ to be a vector or positive income streams of household $i$ over $t$ periods. The estimate of time-mean is therefore $\hat{\bar{y}}_{i}=\frac{1}{t} \sum_{j=1}^{t} y_{i j}$, where $y_{i j}$ is period $j$ consumption (or income) of household $i$. We take $\hat{\bar{y}}_{i}$ as a surrogate for unobserved permanent income $\bar{y}_{i}=\int_{-\infty}^{\infty} y d F_{i}(y)$, where $F_{i}(y)$ is the household-specific distribution function from which observed household $i$ income over time are drawn. It should be noted that the observed incomes are randomly distributed around the unobserved 
permanent income, so that true permanent income is the expected value of income over $F_{i}(y)$, and temporal income $y_{i j}$ is drawn from the distribution $F_{i}(y)$.

\section{JR's chronic poverty definition}

We measure poverty here using the squared poverty gap (SPG) index because it accounts for sensitivity "dispersal" and "unevenness" in income among the poor. This means minimal balancing transfer from a poor person to a poorer person diminishes the measured poverty gap, $p\left(y_{i j}\right)$. The SPG for household $i$ is, $p\left(y_{i j}\right)=\left(1-y_{i j}\right)^{2}$.

We note that $y_{i j}$ is normalized to the poverty line, i.e., $y_{i j} / z$, where $z$ is a given timeinvariant poverty line in real terms - remains fixed over time. Following this, an individual $i$ at time $j$ with $y_{i j}=1$ is precisely at the poverty line; deemed to be poor if $y_{i j}<1$ and nonpoor if $y_{i j}>1$. The measure of chronic poverty is therefore:

$$
\mathrm{C}\left(y_{i}\right)=\frac{1}{t} \sum_{j=1}^{t}\left(1-\hat{\bar{y}}_{i}\right)^{2}
$$

Summing this across all individuals we obtain the estimate of total poverty as defined by JR:

$$
P\left(y_{i}\right)=t^{-1} \sum_{i=1}^{t}\left(1-y_{i j}\right)_{+}^{2},
$$

where $f_{+}=\max (f, 0)$ indicates we are interested in only positive values of $P\left(y_{i}\right)$. It follows that, stochastic (or transient) poverty is the difference between total poverty $P\left(y_{i}\right)$ and chronic poverty $\mathrm{C}\left(y_{i}\right)$ :

$$
T\left(y_{i}\right) \equiv P\left(y_{i}\right)-\mathrm{C}\left(y_{i}\right)
$$

\section{Correcting for biases in JR's: accounting ill-fares using EDE poverty gaps}

JR proposes $\frac{1}{t} \sum_{j=1}^{t}\left(1-\hat{\bar{y}}_{i}\right)_{+}^{\alpha}$ as $i$ 's estimate of chronic poverty.

Summing over individual $n$ and across time, we obtain aggregate chronic poverty:

$$
P_{\alpha}(y) \equiv(n t) \frac{1}{t} \sum_{i=1}^{n} \sum_{j=1}^{t}\left(1-\hat{\bar{y}}_{i}\right)_{+}^{\alpha}
$$


In this respect we consider poverty as the aggregation of "ill-fares" in welfare levels in society. Analogous to Atkinson's (1970), let $\lambda_{\alpha}\left(\mathrm{g}_{i}\right)$ be the "equally distributed equivalent" (EDE) poverty gap for individual $i$ (where $g_{i}$ denotes household's $i$ poverty gap, i.e., individual poverty gap). That is, the level of ill-fare which if equally transferred to all individuals at all times will leave the poverty measure, arising from the distribution of the normalized poverty gap, unchanged. In this manner, if $\alpha>1$ and using (3.10), the EDE poverty gap is:

$$
\zeta_{\alpha}(\mathrm{g})^{\alpha} \equiv P_{\alpha} \zeta(\mathrm{g})
$$

and thus we have:

$$
\zeta_{\alpha}(\mathrm{g})^{\alpha} \equiv \mathrm{P}_{\alpha} \zeta(\mathrm{g})^{\frac{1}{\alpha}}
$$

$\zeta_{1}(\mathrm{~g})$ is the average poverty gap under the setting $\alpha=1$, and therefore not sensitive to inequality in ill-fare and poverty eminences below the poverty line. In contrast to the counterfactual measure of poverty gap, i.e., the EDE gap $\lambda_{\alpha}\left(\mathrm{g}_{i}\right)$, this attribute raises the social cost of poverty. By default, a setting of $\alpha \geq 1$ is indispensable in obtaining among the poor an inequality-sensitive measure of poverty.

Consider: if everyone has the same normalized poverty gap, then $\zeta_{\alpha}(\mathrm{g})=\zeta_{1}(\mathrm{~g})$, otherwise there exists a cost of inequality $\emptyset_{\alpha}(\mathrm{g})$ (i.e., unequal distribution of individual "ill-fare" and normalized poverty gaps), and this cost is amplified the larger $\alpha$ is. The cost is captured by:

$$
\emptyset_{\alpha}(\mathrm{g}) \equiv \zeta_{\alpha}(\mathrm{g})-\zeta_{1}(\mathrm{~g})
$$

$\emptyset_{\alpha}(\mathrm{g})$ is interpreted as the opportunity cost, arising from rise in $\zeta_{1}(\mathrm{~g})$, that the social decision maker (SDM) would have to bear to eliminate existing poverty gaps without a corresponding rise or fall in aggregate poverty. Accounting for the cost of inequality, total poverty can be expressed as:

$$
\zeta_{\alpha}(\mathrm{g}) \equiv \zeta_{1}(\mathrm{~g})+\emptyset_{\alpha}(\mathrm{g})
$$

Since fluctuations in consumptions, particularly around time-mean and poverty line, produce transient poverty and therefore inequality in individual ill-fares, by default, one can use the above established framework in accounting for the inequality cost of transient poverty. Let $\lambda_{\alpha}\left(\mathrm{g}_{i}\right)$ be the EDE poverty gap (adjusted i.e., for variability) for individual $i$ :

$$
\lambda_{\alpha}\left(\mathrm{g}_{i}\right) \equiv\left(\frac{1}{t} \sum_{i=1}^{t} \mathrm{~g}_{i j}^{\alpha}\right)^{\frac{1}{\alpha}}
$$


then the transient component cost of inequality in ill-fare status is:

$$
\delta_{\alpha}\left(\mathrm{g}_{\mathrm{i}}\right) \equiv \lambda_{\alpha}\left(\mathrm{g}_{i}\right)-\lambda_{1}\left(\mathrm{~g}_{i}\right)
$$

$\delta_{\alpha}\left(\mathrm{g}_{\mathrm{i}}\right)>0$ is the cost, over time, to individual $i$ if he is to eliminate his ill-fare status. But if $\delta_{\alpha}\left(\mathrm{g}_{\mathrm{i}}\right)=0$, then there is no transient poverty, as income (or consumption) streams do not vary around the poverty line. Aggregate transiency, summing $\delta_{\alpha}\left(\mathrm{g}_{\mathrm{i}}\right)$ over $n$ individuals, is:

$$
\eta_{\alpha}(\mathrm{g})=\frac{1}{n} \sum_{i=1}^{n} \delta_{\alpha}\left(\mathrm{g}_{\mathrm{i}}\right)
$$

Let us now focus on the distribution of the individual EDE poverty gaps $\lambda_{\alpha}\left(\mathrm{g}_{i}\right)$. Given $\lambda_{\alpha} \equiv\left(\lambda_{\alpha}\left(g_{1}\right), \ldots, \lambda_{\alpha}\left(g_{n}\right)\right)$ as the distribution of individual ill-fare in the embedding of both individual chronic and transient poverty and accounting for $\lambda_{\alpha}$, aggregate poverty then becomes:

$$
\zeta_{\alpha}\left(\lambda_{\alpha}\right)=\left(\frac{1}{n} \sum_{i=1}^{n} \lambda_{\alpha}\left(\mathrm{g}_{i}\right)^{\alpha}\right)^{1 / \alpha}
$$

and the cost of EDE inequality between individuals is:

$$
\emptyset_{\alpha}\left(\lambda_{\alpha}\right) \equiv \zeta_{\alpha}\left(\lambda_{\alpha}\right)-\zeta_{1}\left(\lambda_{\alpha}\right)
$$

Total poverty in this regard is, therefore, the sum of the average poverty gap in the population $\zeta_{1}(\lambda)$, the cost of inequality in individual EDE poverty gaps $\emptyset_{\alpha}\left(\lambda_{\alpha}\right)$, and the cost of transient poverty $\eta_{\alpha}(\mathrm{g})$ :

$$
\zeta_{\alpha}(\lambda)=\zeta_{1}(\lambda)+\emptyset_{\alpha}\left(\lambda_{\alpha}\right)+\eta_{\alpha}(\mathrm{g})
$$

Chronic poverty is hence denoted as:

$$
\zeta^{*}(\lambda)=\zeta_{1}(\lambda)+\emptyset_{\alpha}\left(\lambda_{\alpha}\right)
$$

Therefore, total poverty is the sum of chronic and transient poverty:

$$
\zeta_{\alpha}(\lambda)=\zeta^{*}(\lambda)+\eta_{\alpha}(\mathrm{g})
$$


The total cost of inequality in normalized poverty gaps $\emptyset_{\alpha}(\lambda)$ is the sum of the cost of inequality between individuals $\emptyset_{\alpha}\left(\lambda_{\alpha}\right)$ and that of inequality across time $\eta_{\alpha}(\mathrm{g})$ :

$$
\emptyset_{\alpha}(\lambda)=\emptyset_{\alpha}\left(\lambda_{\alpha}\right)+\eta_{\alpha}(\mathrm{g})
$$

\section{Estimating transient and chronic poverty models}

Having defined transient and chronic poverty at the household level, I want to examine whether the household and geographic characteristics that one would typically identify as important in determining static poverty also influence the extent of chronic and transient poverty. That is, is there any evidence in my dataset that different household characteristics have different effects on the two components of poverty, or do their effects tend to be the same?

To address these questions, I estimate three models where I regress the measures of total, chronic, and transient poverty on the same set of household characteristics. My model for either total $(\mathrm{T})$, chronic $(\mathrm{C})$ or transient $(\mathrm{T})$ poverty is:

$$
\begin{aligned}
P_{i} & =P_{i}^{*} \text { if } P_{i}^{*}>0, \\
& =0 \text { otherwise; }
\end{aligned}
$$

where,

$P_{i}$ is observed

$P_{i}^{*}$ is an unobserved latent variable, with $P_{i}^{*}=Z_{i} \delta+\varepsilon_{i}(4.24)$

$\delta$ is a $q x 1$ vector of unknown parameters of interest to be estimated

$Z_{i}$ is a $1 x q$ vector of controls, made up of household demographics; and $\varepsilon_{i}$ is the model residual, assumed to be identically distributed; independent of the regressors, having a zero- median, and with the distribution function continuously differentiable with density bounded above and positive at zero.

To estimate the specification such as (4.1), the usual practice is to use censored regression estimation techniques, (e.g., Tobit model) in that, the underlying error distribution is assumed to be normal. However, the maximum likelihood estimation (MLE) of Tobitobtained parameters are not robust to misspecifications and are also inefficient in the presence of heteroscedasticity and/or non-normality in the errors (Powel, 1983; and Ravallion, 1998). In addition, the Tobit estimator for $\delta$ is MLE when the residual, $\varepsilon_{i}$, is orthogonal to $Z_{i}^{\prime}$ and $N\left(0, \sigma^{2}\right)$, but $\delta$ is not identifiable through moment restrictions, save as the conditional median of $y_{i}, Z_{i}^{\prime} \delta$ is, so that, 


$$
\operatorname{Med}\left(Z_{i}^{*} \mid Z_{i}\right)=Z_{i}^{\prime} \delta(4.25)
$$

Given that,

$$
\begin{gathered}
\operatorname{Med}\left(p_{i}^{*} \mid Z_{i}\right)=\max \left(\operatorname{Med}\left(p_{i}^{*} \mid Z_{i}\right), 0\right), \\
=\max \left(Z_{i}^{\prime} \delta, 0\right)(4.26)
\end{gathered}
$$

the conditional median is a specific nonlinear function of the single index $\delta^{\prime} Z_{i}$. Therefore, observations for which $P_{i}>0$, obeys the nonlinear median regression model,

$$
\begin{gathered}
p_{i}^{*}=\max \left(Z_{i}^{\prime} \delta, 0\right)+\varepsilon_{i}(4.27) \\
\operatorname{Med}\left(\varepsilon_{i} \mid Z_{i}\right)=0 .
\end{gathered}
$$

Given the obvious flaws (i.e., the non-robustness of parameters to conditional heteroscedasticity and distributional misspecification of the error term) of the Tobit-type estimators, based on Powel (1983), I use a semi-parametric estimator: censored least absolute deviations (CLAD). CLAD is considered the most appropriate estimator for this kind of exercise because it allows for the censored data structure and the parameters obtain using this estimator are robust to the presence of heteroscedasticity. This is because the condition median of the dependent variable will still be of the form $\left[0, Z_{i}^{\prime} \delta\right]$, which can be defined as the minimizer of the sample average absolute deviation of $P_{i}$ from its conditional median function $(\delta>0)$.

The minimization function is:

$$
Q_{n}(\delta ; \theta)=\frac{1}{N} \sum_{i=1}^{N} \rho_{\theta}\left[P_{i}-\max \left(0, Z_{i}^{\prime} \delta\right)\right](4.28)
$$

or

$$
S_{n}(\delta)=\sum_{i=1}^{n} 1\left(Z_{i}^{\prime} \delta>0\right)\left|P_{i}-Z_{i}^{\prime} \delta\right|
$$

The estimator $\hat{\delta}$, which minimizes $S_{n}(\delta)$ is called the CLAD estimator. The estimator satisfies the asymptotic First Order Condition (FOC):

$$
\sum_{i=1}^{n} 1\left(Z_{i}^{\prime} \hat{\delta}>0\right) z_{i} \operatorname{sgn}\left(P_{i}-Z_{i}^{\prime} \hat{\delta}\right)=0
$$

The consistency of this estimator rests on the fact that medians are preserved by monotone transformations of the data, and (4.1) is a monotone transformation of the standard least absolute deviations (LAD) regression. 
The estimation technique for CLAD estimator is the Iterative Linear Programming Algorithm (ILPA) proposed by Buchinsky (1994). The ILPA follows the following process: (i) a quantile regression for the full sample is estimated; (ii) observations with predicted values of the dependent variable that are less than zero are delated. Finally, (i) and (ii) are repeated until there is convergence (i.e. when there are no negative predicted values in two consecutive iterations), when a local minimum is obtained. The entire algorithm described above is repeated for each bootstrap resampling of the data.

Analogous to (4.1), our models (to be estimated) for Chronic $\left(C_{i}^{*}\right)$ and Transient poverty $\left(T_{i}^{*}\right)$ respectively, are:

$$
\begin{aligned}
& T_{i}^{*}=Z_{i} \delta^{T}+\varepsilon_{i}^{T}(4.31) \\
& C_{i}^{*}=Z_{i} \delta^{C}+\varepsilon_{i}^{C}(4.32)
\end{aligned}
$$

I now proceed to obtain my parameters of interest $\left(\delta^{P}, \delta^{T}\right.$ and $\left.\delta^{C}\right)$ using CLAD. My outcome variables, $C_{i}^{*}$ and $T_{i}^{*}$, were constructed using JR's chronic and transient poverty definitions.

To estimate my specifications in (7.3) and (7.4), I control for the characteristics of household heads: age, age squared, household size, household size squared, and years of schooling of household head. I also control for the following dummies: household living in oil producing state, household living in urban area and household head is male. These controls were selected based on the literature of poverty mapping (Elbers et al., 2003; Ravallion, 1995, Mukherjee and Benson, 2003; Dang 2014, et al.). 
Table 1. Regression: PCE and household characteristics

\begin{tabular}{lllll}
\hline & 1980 & 1992 & 1996 & 2010 \\
\hline Age of head & -0.00887 & -0.00791 & $-0.0353^{*}$ & 0.00132 \\
& $(0.013)$ & $(0.019)$ & $(0.017)$ & $(0.016)$ \\
Age squared & 0.000180 & 0.000106 & $0.000524^{*}$ & 0.0000403 \\
Household size & $(0.000)$ & $(0.000)$ & $(0.000)$ & $(0.000)$ \\
& $-0.291^{* * *}$ & $-0.251^{* * *}$ & $-0.322^{* * *}$ & $-0.372^{* * *}$ \\
Household size squared & $(0.004)$ & $(0.007)$ & $(0.009)$ & $(0.009)$ \\
& $0.00528^{* * *}$ & $0.00647^{* * *}$ & $0.0131^{* * *}$ & $0.0193^{* * *}$ \\
Place of residence (urban=1) & $(0.000)$ & $(0.000)$ & $(0.001)$ & $(0.001)$ \\
& $0.138^{* * *}$ & $0.123^{* * *}$ & $0.158^{* * *}$ & $0.113^{* * *}$ \\
Gender of head (male=1) & $(0.017)$ & $(0.021)$ & $(0.020)$ & $(0.012)$ \\
Living in oil state & $0.131^{* * *}$ & $0.283^{* * *}$ & $0.173^{* * *}$ & $0.0582^{* * *}$ \\
Years of schooling & $(0.028)$ & $(0.030)$ & $(0.026)$ & $(0.016)$ \\
& $0.0600^{*}$ & $0.230^{* * *}$ & $0.245^{* * *}$ & $0.0979^{* * *}$ \\
Constant & $(0.025)$ & $(0.030)$ & $(0.028)$ & $(0.016)$ \\
& 0.00382 & $0.0177^{* * *}$ & $0.0209^{* * *}$ & $0.0238^{* * *}$ \\
\hline R ${ }^{2}$ & $(0.002)$ & $(0.002)$ & $(0.002)$ & $(0.001)$ \\
Obs & $13.13^{* * *}$ & $12.40^{* * *}$ & $12.45^{* * *}$ & $12.07^{* * *}$ \\
\hline
\end{tabular}

Standard errors in parentheses; ${ }^{*} p<0.05,{ }^{* *} p<0.01,{ }^{* * *} p<0.001$; Source: Data Household Surveys of Nigeria sweeps 1 to 6

Notes:

1. Model 1 was used in obtaining 1980 (round 1) consumption of households surveyed in 1985 (round 2) and model 2 in obtaining round 3's for the same households, so that we have three-period consumption for the same households.

2. The dependent variable is the log of consumption per capita, $\ln \mathrm{y}_{\mathrm{it}}$

\section{Data}

The household surveys used in this study were collected under the National Integrated Survey of Households (NISH). They include the National Consumer Surveys (NCS), collected in 1980, 1985, and 1992; the 2003/2004 Nigeria Living Standard Survey (NLSS); and the 2009/2010 Harmonized Nigeria Living Standard Survey (HNLSS). The surveys were conducted by the National Bureau of Statistics, Nigeria (NBS), formerly the Federal Office of Statistics, in collaboration with the World Bank, UK Department for International Development (DFID), United Nations Children's Fund (UNICEF), and the European Union. Information about the sample years and sizes of the six surveys are shown in Table 2. 
Table 2. Number of surveyed households and population in Nigeria, $1980-2010$

\begin{tabular}{cccc}
\hline Year of Survey & $\begin{array}{c}\text { Sample Size } \\
\text { (No. of households) }\end{array}$ & $\begin{array}{c}\text { Households } \\
\text { (Million) }\end{array}$ & $\begin{array}{c}\text { Population size } \\
\text { (Million) }\end{array}$ \\
\hline 1980 & 10,280 & 17.30 & 73.69 \\
1985 & 9,317 & 18.80 & 74.7 \\
1992 & 9,697 & 20.70 & 99.2 \\
1996 & 14,395 & 24.50 & 120 \\
2004 & 19,158 & 26.60 & 126 \\
2010 & 34,799 & 38.30 & 159.7 \\
\hline \hline
\end{tabular}

Sources: Household surveys of Nigeria 1980-2010, NBS; and The World Bank

In terms of sampling design, all surveys were national in coverage; they included all states, rural and urban areas, under a two-stage design. The first stage was made up of clusters of housing units (HUs) called enumeration areas (EAs). The EAs were drawn from each state (stratum) of the federation. The second stage involved the selection of HUs (see FOS (1999) and NBS (2012b); Anyanwu (2005); Appleton et al. (2008); Canagarajah and Thomas (2001) (for details).

The samples were weighted. Two types of weights were used in constructing estimates: one for households and one for individuals. The household weight, $\boldsymbol{\omega} \_\boldsymbol{h}, \boldsymbol{h}=\mathbf{1}, \ldots, \boldsymbol{H}$ is equal to the number of households represented by a particular respondent household. The sum of all the weights equals the total number of households (not individuals) in the country.

The second is the individual weight. Since households are made up of individual(s), the weight for an individual, $\psi_{j}, j=1, \ldots, N$, in each household is obtained by multiplying the weight attached to the household $\left(\omega_{h}, h=1, \ldots, H\right)$ to which the individual belongs by the total number of individuals in the household (household size). The sum of these (across all the observations) equals the country's total population. The weights are then used in constructing estimates of population parameters for households and for the individuals.

\section{The National Consumer Surveys (NCSs)}

The surveys follow a 12-month cycle, March to April. Four NCSs were carried out between 1980 and 1996. The sampling frames, under a two-stage design, were based on the country's 1980 population census. In the first stage, a random sample of 1,500 clusters (EAs) were selected out of a total of 4,000 in the entire country; for the second stage, a random sample of 5 to 15 households was drawn from each of the EAs. For the 1985 and 1992 surveys, 1,224 EAs were selected, proportionate to the number of census households in the area. The delamination criteria were based on states of residence. In each state, 40 and 30 EAs were drawn from urban and rural areas, respectively. 


\section{The $2003 / 2004$ NLSS}

In terms of sample design, the first stage of the 2004 NLSS survey was made up of 120 (and 60 from the FCT) clusters of HUs in each of the 36 states of the federation. The clusters were selected based on 12 replicates, 10 clusters per replicate and then 5 HUs per replicate. Finally, $600 \mathrm{HUs}$ (and 300 from the federal capital) were covered in each state, leading to a total of approximately 21,900 HUs surveyed for the entire country within a 12-month period. There were seven interviewer visits to each selected household on a minimum frequency of a four-day interval in a cycle of 30 days. A diary of daily consumption and expenditure as one of their survey instruments in the collection consumption data.

\section{The 2009/2010 HNLSS}

One hundred households were sampled from each of the 774 local government areas (LGAs) in the country, i.e., a total of 77,400 households for the entire country. For the survey of consumption expenditures, the sample size per LGA was later restricted to 50, resulting in 38,700 households for the entire survey. A two-stage sample design was adopted in the survey. Like previous surveys, the clusters constituted the first stage or primary sampling units, and then the selection of households the second stage. The sampling frame was delineated by the National Population Commission based on the 2006 Housing and Population Census. The frame was made up of replicates three in each of the LGAs.

Field staff usually made daily visits to each household to ensure the quality of the data entry and also to help households without a literate member who could fill in the diary. This information was then transferred daily to the enumerator's memo book. The enumerator's book was then checked for quality and consistency by the field office supervisor. For each household, the survey collected information on (a) household demographic statistics (age, gender, location, and type of housing of the household); (b) household expenditure (expenditure on all goods and services incurred by the household during the survey period and all monetary transactions); and (c) imputed rent on owner-occupied and rent-free dwelling.

\subsection{Definition of poverty lines in Nigeria}

Attempts to measure poverty in Nigeria use different poverty lines as the country has no official line. As a measure of absolute poverty, Sudharshan, Ngwafon, and Saji (2001), FOS (1999); and Ayanwu $(2005,2010)$ used two-thirds of mean consumption per capita expenditures in the 1985 survey, i.e., $\$ 395.4$ per person per annum in 1985 prices. This is equivalent to $\$ 5,795.36$ per person per month in July 2016 prices. This line was later adjusted, using CPI, for estimating poverty in the 1980-96 poverty profile released by the FOS, now NBS.

In its 2004 and 2010 poverty reports, the NBS derived and adopted higher lines in measuring absolute poverty in the country. In 2004 , a per year line of $\$ 30,128$ was used, equivalent to $\$ 7,804.72$ per person per month in July 2016 prices. In 2010, an annual line of $\$ 54,401.16$ per year (or 7,406.70 in July 2016 prices). In real terms, the 2004 line was higher than that of 2010. In deriving the 2010 absolute poverty line, the NBS used 3,000 calories as the 
expected minimum caloric intake for the average Nigerian as recommended by a nutrition consultant as the reasonable benchmark for Nigeria given its average food basket. For 2004, NBS calculated a minimum annual expenditure required per equivalent adult as 21,743 on food to attain 2900 calories per person per day. This expenditure on food constitutes the threshold for extreme poverty.

Since the 395.4 poverty line was expressed in 1985 prices, I multiplied the 1980 CPI value of 0.44 (found in the poverty profile of 1999) by this line, thus converting it to 1980 prices. This gives 173.8 per person per year. I multiplied this by the 2015 CPI value of 388.87 (base $=1980$ ) to get the poverty line in 2015 prices. Finally, I revalued this line to account for the recent rise in cost of living: by multiplying by 1.028 (the CPI of July 2016, base=December 2015). I applied a similar approach in converting the US $\$ 1.25$ to more recent prices. First, we used the 2005 PPP Nigerian exchange rate value of 78.58 from the World Bank. Note, absolute poverty lines reflect the standards of absolute poverty in the world's poorest countries corresponding to the same real level of well-being in all countries. I take those same lines (expressed in local currency units at 2005 prices), and inflate them to July 2016 using Nigeria's CPI.

As defined by the World Bank, this line is the mean of cost of basic needs of poverty lines across the 15 poorest countries of the world (see Chen and Ravallion (2008) and Sangraula et al. (2008) for details). In other words, it measures how poor people are by the standards used to define poverty in the poorest countries of the world. Before using this line, I revalued the consumption distributions for all the years to correspond with this line. ${ }^{1}$ The international poverty line is converted to local currencies in the corresponding International Comparison Program (ICP) benchmark and is then converted to the prices prevailing at the time of the relevant household survey using the available CPI for Nigeria.

The cost-of-basic-needs approach calculates the cost of a bundle of goods deemed sufficient for "basic needs." It first estimates the cost of acquiring enough food for adequate nutrition - usually 2,100 calories per person per day — and then adds the cost of other essentials, such as clothing and shelter. But when price information is unavailable, the food energy intake method can be used. This method plots expenditure per capita against food consumption (in calories per person per day) to determine the expenditure (or income) level at which a household acquires enough food (Haughton \& Khandker, 2009).

\section{Discussion of findings}

I begin this section by presenting and results from spell-based approach. The results presented here were obtained using Dang et al. (2014)'s spell-based approach to measuring poverty dynamics. Based on this approach, my intent is to study the movements in income (or consumption) of households around a defined poverty line. The results presented in Table 3, Table 4, and Table 5 shows the pattern of such movements. For instance, the

\footnotetext{
${ }^{1}$ We do not use adult equivalence (AE) scales for 1980-96 surveys because of the lack of information (e.g. age and number of children in each household) required for computing the AE.
} 
mobility estimates between two rounds (1980 and 1985) shown in Table 3 are grouped into four typologies of poverty (Column 1) or poverty experiences (Column 2). Recall, we used a synthetic panel for this exercise as Nigeria has no actual panel. The synthetic panel is made up of consumption estimates obtained using linear projections for periods for which a survey was not conducted. For example, I estimate 1980 consumptions $\left(y_{1}\right)$ for households surveyed in $1985\left(y_{2}\right)$. For robustness, as explained in the methodology for constructing synthetic panel, the consumption estimates were obtained in two ways. The first involves taking random draws of predicted residuals - the "upper bound" consumption estimate. Second, instead of taking random draw, ratio of round 1 to round 2 of the predicted residuals were included in the linear projection equation. I call this the "lower bound" consumption estimate.

Row 1, Column 3 of Table 3 shows the fraction (i.e. 42.20 percent) of the total population, based on the lower bound consumption estimate, that is poor in 1980 and also poor in 1985. Further, Row 1, Column 2 of the same Table shows the same fraction (i.e. 31.87 percent) but based on the upper bound consumption estimate. In their study of poverty mobility based on synthetic panel, Dang et al. (2014) demonstrate using actual panel, that the "true rate" of poverty mobility is sandwiched between the lower and upper bound estimates. In our case, the actual proportion of households that are poor both in 1980 and 1985 is sandwiched between 31.87 and 42.20 percent. It should be noted that, the terms "upper" and "lower" bounds do not refer to a range but to estimates obtained from predicted consumptions using lower and upper bounds non-parametric approaches. Hence, the "lower" estimate for a type can happen to exceed the corresponding "upper" estimate.

Table 3. Spell-based non-parametric rates of poverty mobility estimates (\%), 1980-85 (5 years)

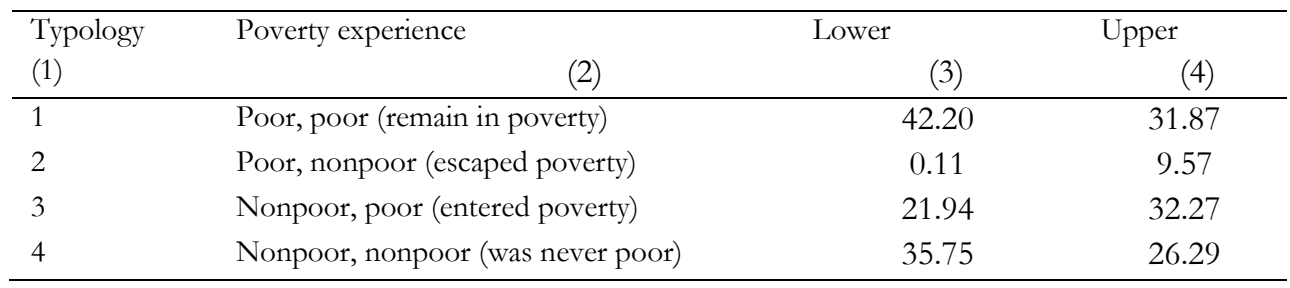

Source: Author's computation based on household surveys of Nigeria

Note: 'The terms 'Upper' and 'Lower' bounds do not refer to within a range but to estimates obtained from predicted consumptions using lower and upper bounds non-parametric approaches. Hence, the 'Lower' estimate for a type can happen to exceed the corresponding 'Upper' estimate."

About 0.11 and 9.57 percent of poor households in 1980 managed to move out of poverty by 1985 (row 2, columns 3-4 of Table 3), but around 21.94 and 32.27 percent of non-poor households fell into poverty (row 3, columns 3 and 4 of Table 3) in 1985. Further, 26.2935.75 percent of the entire population stayed out of poverty (row 4, columns 3 and 4 of Table 3), as their consumptions in both periods were above the poverty line. In terms of demographics, majority of those in this category are schooled, live in urban areas, and found in the top 10th decile of the income distribution, making them less vulnerable to transition into poverty. 
To see how the dynamic poverty profile reveals the extent to which static profile understates the extent of poverty, we compare the static poverty rate in 1985 and the results of poverty dynamics presented in Table 3. The poverty rate in 1985, from observed (not predicted) consumption, was 64.12 percent. But between 1980 and 1985, more than this proportion of the population has experienced one form of poverty or another-some households move in, some exit. If we sum up, using the "upper bound" estimate from the table (column 4), the values in rows 1-3, we get the fraction of the entire population that experienced poverty between 1980 and 1985, i.e., 73.71 percent. Subtracting the static poverty rate, 64.12 percent from the dynamic poverty rate 73.71 percent, $[=73.71-64.12$ percent $]$, we get the rate at which the static profile understates the extent of poverty experience. Clearly, the static poverty rate has underestimated, between 1980 and 1985, the extent of poverty by 9.5 percentage points.

Table 4 reports the pattern of poverty mobility between three rounds (1980, 1985, and 1992). Based on the lower bound estimates, summing rows 1-7 from column 5 of the table, we find low rate of poverty mobility, as only 24.53 percent of the entire population experienced movements into and out of poverty. Row 8 shows that, using the "lower and upper bound estimates" respectively, 13.25-34.65 percent of the population lived above the poverty threshold throughout the 12 -year period.

Table 4. Three-round spell-based non-parametric rates of poverty mobility (\%) 1980, 1985, 1992

\begin{tabular}{|c|c|c|c|c|c|c|}
\hline $\begin{array}{l}\text { Poverty } \\
\text { typology }\end{array}$ & 1980 & 1985 & 1992 & Lower bound & & Upper bound \\
\hline (1) & (2) & (3) & (4) & (5) & & (6) \\
\hline 1 & Poor & poor & poor & 40.83 & - & 26.88 \\
\hline 2 & Poor & poor & nonpoor & 1.37 & - & 4.99 \\
\hline 3 & Poor & nonpoor & nonpoor & 0.07 & - & 2.12 \\
\hline 4 & Poor & nonpoor & poor & 0.04 & - & 7.45 \\
\hline 5 & Nonpoor & poor & nonpoor & 1.1 & - & 13.04 \\
\hline 6 & Nonpoor & poor & poor & 15.04 & - & 21.7 \\
\hline 7 & Nonpoor & nonpoor & poor & 6.91 & - & 10.57 \\
\hline 8 & Nonpoor & nonpoor & nonpoor & 34.65 & - & 13.25 \\
\hline
\end{tabular}

Source: Author's computation based on household surveys of Nigeria.

Notes:

1. 'The terms 'Upper' and 'Lower' bounds do not refer to within a range but to estimates obtained from predicted consumptions using lower and upper bounds non-parametric approaches. Hence, the 'Lower' estimate for a type can happen to exceed the corresponding 'Upper' estimate."

2. Based on column (5), over 1980-1992 (i.e. 12 years), 86.51\% (summing column 5 from row 1 one to row 7) of the population experienced poverty. Of this percentage, $31.92 \%$ were poor throughout the period, while $54.59 \%$ move in and out of poverty. 
Table 5. Three-round spell-based non-parametric rates of poverty mobility (\%)1996, 2004, 2010

\begin{tabular}{lllllll}
\hline $\mathrm{P}$ & 1996 & 2004 & 2010 & Lower bound & Upper bound \\
\hline$(1)$ & $(2)$ & $(3)$ & $(4)$ & $(5)$ & - & 29.33 \\
\hline 1 & Poor & Poor & Poor & 56.38 & - & 12.19 \\
2 & Poor & Poor & nonpoor & 0.06 & - & 8.67 \\
3 & Poor & nonpoor & nonpoor & 0.01 & - & 15.79 \\
4 & Poor & nonpoor & poor & 10.19 & - & 6.01 \\
5 & Nonpoor & Poor & nonpoor & 30.42 & - & 9.48 \\
6 & Nonpoor & Poor & poor & 2.8 & - & 8.27 \\
7 & Nonpoor & nonpoor & poor & 0.01 & - & 10.26 \\
8 & Nonpoor & nonpoor & nonpoor & 0.12 & & \\
\hline
\end{tabular}

Source: Author's computation based on household surveys of Nigeria

Note: 'The terms 'Upper' and 'Lower' bounds do not refer to within a range but to estimates obtained from predicted consumptions using lower and upper bounds non-parametric approaches. Hence, the 'Lower' estimate for a type can happen to exceed the corresponding 'Upper' estimate."

If we take the sum of rows 1, 4, 6 and 7 under either column 5 (or 6), we get the static poverty rate for the most recent year, 2010. The rate is 62.8 percent (or 66.6 percent). This rate was derived using the 2010 (round 3) predicted consumptions for households that were surveyed in 2004 (round 2). However, the poverty rate using 2010 cross-section (not predicted, not for the households surveyed in 2004, but observed from households independent of 2004's) consumption, is slightly higher than this, approximately 70 percent.

We now contrast the poverty mobility results in Table 4 (poverty mobility between 1980-92) with Table 5's (poverty mobility between 1996-10). As can be seen, the fraction of the total population that experienced movements in and out of poverty rose substantially, from 24.53 percent in 1980-92 period to 60.41 percent in 1996-10 period. Clearly, this shows that the degree of poverty mobility around the defined poverty line has risen, and that more households, over time, have recorded changes in their economic status relative to the poverty line. The proportion of those that were poor in all the three rounds (comparing row 1 in both tables based on the lower bound estimate) has risen by 15.55 percentage points. Also, the fraction of the population of the population that never experienced poverty declined from about 35 percent (row 8, column 5 of Table 4) to about 10 percent (row 8, column 5 of Table 5). Dang et al. (2014) carried out similar studies with from Indonesia (1997-2000) and Vietnam (2006-2008). They found lower rate of chronic poverty in both countries, with over 80 percent of the population living above the defined poverty lines in both rounds.

\subsection{Results from component-based approach}

In Table 6, we report JR's transient and chronic poverty measures. Chronic poverty, unadjusted for bias, represents 94 percent (based on lower bound, last row column 2 of Table 6), or 55 percent (based on upper bound, last row, column 3 of Table 6) of total poverty. Taking into account asymptotic correction bias lowers this estimate to about 90 percent (column 3, last row) and 38 percent (column 4, last row). 
Table 6. JR's transient and chronic poverty measures 1980-92; $\alpha=2 ; \mathrm{t}=3$

\begin{tabular}{|c|c|c|c|c|}
\hline \multirow[b]{2}{*}{ Components of poverty } & \multicolumn{2}{|c|}{ Without bias corrections } & \multicolumn{2}{|c|}{ With bias corrections } \\
\hline & $\begin{array}{c}\text { Lower bound } \\
\text { (1) }\end{array}$ & $\begin{array}{l}\text { Upper bound } \\
\text { (2) }\end{array}$ & $\begin{array}{c}\text { Lower bound } \\
\text { (3) }\end{array}$ & $\begin{array}{c}\text { Upper bound } \\
\text { (4) }\end{array}$ \\
\hline \multirow[t]{2}{*}{ Transient $T\left(y_{i}\right)$} & 0.007 & 0.067 & 0.011 & 0.093 \\
\hline & $(0.000)$ & $(0.001)$ & $(0.000)$ & $(0.001)$ \\
\hline \multirow[t]{2}{*}{ Chronic $\mathrm{C}\left(y_{i}\right)$} & 0.108 & 0.082 & 0.104 & 0.057 \\
\hline & $(0.003)$ & $(0.003)$ & $(0.000)$ & $(0.005)$ \\
\hline \multirow[t]{2}{*}{ Total } & 0.115 & 0.149 & 0.115 & 0.149 \\
\hline & $(0.003)$ & $(0.003)$ & $(0.003)$ & $(0.003)$ \\
\hline \multicolumn{5}{|l|}{ Ratios } \\
\hline Transient/Chronic & 0.065 & 0.817 & 0.106 & 1.63 \\
\hline Chronic/Total & 0.939 & 0.550 & 0.904 & 0.382 \\
\hline
\end{tabular}

Source: Author's computation based on household surveys of Nigeria

Note: “The terms 'Upper' and 'Lower' bounds do not refer to within a range but to estimates obtained from predicted consumptions using lower and upper bounds non-parametric approaches. Hence, the 'Lower' estimate for a type can happen to exceed the corresponding 'Upper' estimate."

Essentially, the ratio of transient to chronic poverty is a function of the extent of the pool of the poor; such that in societies with fewer poor people, the ratio tends to be large. My results show that, with and without bias correction based on lower bounds consumption estimates, the ratio is quite low-it ranges between 0.065 and 0.106 (second to the last row of the table). This and the share of chronic poverty in total poverty gives a bleak picture of the extent of poverty in Nigeria.

Disaggregating these findings by household demographics (results not reported here) shows that relatively smaller households (1-3 persons) have higher transient than chronic poverty. On the other hand, larger households (7 persons or more) are found to be in chronic poverty. Chronic poverty tends to be higher for households living in rural areas than those in urban areas, and the majority of the rural poor had "permanent consumption" or time-mean below the poverty line.

The North West zone of the country recorded the highest incidence of chronic poverty, with the South-South (the oil producing region) showing the lowest. As one would expect, chronic poverty varies with the level of education. Households with heads who have schooling up to the postsecondary level are less likely to be chronically poor as the proportion is highest among households with no education. Compared to the South, the Northern region is educationally more disadvantaged. This could explain the disparity in the level of chronic poverty between the two regions given the link between education level and chronic poverty. 
Both transient and chronic poverty were higher in 1996-2010 (Table 7) than in the previous 1980-1992 period. But transient poverty rose faster as the share of chronic poverty in total poverty declined to be between 3-55 percent (last row of

Table 7); from about 90 percent. This is an indication that average standards of living have further deteriorated over time. Although total poverty has risen, transient poverty increases relatively rapidly.

Table 7. JR's transient and chronic poverty measures 1996-2010; $\alpha=2 ; \mathrm{t}=3$

\begin{tabular}{lccccc}
\hline \multirow{2}{*}{ Components of poverty } & \multicolumn{2}{c}{ Without bias corrections } & & \multicolumn{2}{c}{ With bias corrections } \\
\cline { 2 - 3 } & Lower bound & Upper bound & & Lower bound & Upper bound \\
\cline { 2 - 3 } Transient $T\left(y_{i}\right)$ & 0.328 & 0.070 & & 0.342 & $(4)$ \\
& $(0.001)$ & $(0.001)$ & & $(0.001)$ & 0.101 \\
Chronic C $\left(y_{i}\right)$ & 0.014 & 0.080 & & 0.0001 & $0.001)$ \\
& $(0.001)$ & $(0.002)$ & & $(0.000)$ & 0.049 \\
Total & 0.342 & 0.150 & & 0.342 & $0.002)$ \\
& $(0.000)$ & $(0.002)$ & & $(0.003)$ & $(0.002)$ \\
Ratios & & & & \\
Transient/Chronic & 23.42 & 0.875 & & 0.000 & 2.06 \\
Chronic/Total & 0.041 & 0.533 & & 0.000 & 0.033 \\
\hline
\end{tabular}

Source: Author's computation based on household surveys of Nigeria

Note: 'The terms 'Upper' and 'Lower' bounds do not refer to within a range but to estimates obtained from predicted consumptions using lower and upper bounds non-parametric approaches. Hence, the 'Lower' estimate for a type can happen to exceed the corresponding 'Upper' estimate."

Table 8 presents the EDE transformation of FGT indices for 1980-1992, with and without bias corrections. ${ }^{2}$ The results are improvements on JR's as they account for intra-individual inequality in ill-fare status. The Social Decision Maker will have to incur 17.89 percent of total poverty to eliminate the observed ill-fare over 1980-92 and about 14-15 percent based on bias-corrected estimates. Using the same data, one observed that JR overstate the extent of transient poverty at the expense of chronic poverty. My ill-fare-adjusted results show higher chronic poverty in share of total poverty than JR's, revealing a relatively true picture of the extent of poverty.

By 1996-2010, chronic poverty, as a share of total poverty across all measures, with and without bias correction, declined substantially. The cost of addressing ill-fare also fell to about 1 percent of total poverty, but the index of total poverty is higher over this period than in 1980-1992.

${ }^{2}$ Although the two bias-correction methods yield almost the same results. 
Table 8. EDE transient and chronic poverty measures 1980-92; $\alpha=2 ; \mathrm{t}=3$

\begin{tabular}{|c|c|c|c|c|c|c|}
\hline \multirow{3}{*}{ Component of poverty } & \multicolumn{2}{|c|}{ Without bias corrections } & \multicolumn{4}{|c|}{ With bias corrections } \\
\hline & \multirow[t]{2}{*}{ Lower bound } & \multirow[t]{2}{*}{ Upper bound } & \multicolumn{2}{|c|}{ Lower bound } & \multicolumn{2}{|c|}{ Upper bound } \\
\hline & & & Analytical & Bootstrap & Analytical & Bootstrap \\
\hline \multirow[t]{2}{*}{ Average gap $\zeta_{1}\left(\lambda_{\alpha}\right)$} & 0.223 & 0.257 & 0.223 & 0.223 & 0.257 & 0.257 \\
\hline & $(0.004)$ & $(0.004)$ & $(0.004)$ & $(0.004)$ & $(0.004)$ & $(0.006)$ \\
\hline \multirow[t]{2}{*}{ Cost of inequality $\emptyset_{\alpha}\left(\lambda_{\alpha}\right)$} & 0.106 & 0.066 & 0.103 & 0.103 & 0.048 & 0.045 \\
\hline & $(0.002)$ & $(0.001)$ & $(0.002)$ & $(0.002)$ & $(0.001)$ & $(0.001)$ \\
\hline \multirow[t]{2}{*}{ Transient $\zeta^{*}(\lambda)$} & 0.010 & 0.063 & 0.012 & 0.012 & 0.081 & 0.084 \\
\hline & $(0.000)$ & $(0.001)$ & $(0.000)$ & $(0.000)$ & $(0.001)$ & $(0.001)$ \\
\hline \multirow[t]{2}{*}{ Chronic $\eta_{\alpha}(\mathrm{g})$} & 0.329 & 0.323 & 0.327 & 0.327 & 0.305 & 0.302 \\
\hline & $(0.005)$ & $(0.004)$ & $(0.005)$ & $(0.005)$ & $(0.004)$ & $(0.004)$ \\
\hline \multirow[t]{2}{*}{ Total poverty $\zeta_{\alpha}(\lambda)$} & 0.339 & 0.386 & 0.339 & 0.339 & 0.386 & 0.386 \\
\hline & $(0.005)$ & $(0.004)$ & $(0.005)$ & $(0.005)$ & $(0.004)$ & $(0.004)$ \\
\hline
\end{tabular}

Source: Author's computation based on household surveys of Nigeria

Note: “The terms 'Upper' and 'Lower' bounds do not refer to within a range but to estimates obtained from predicted consumptions using lower and upper bounds non-parametric approaches. Hence, the 'Lower' estimate for a type can happen to exceed the corresponding 'Upper' estimate."

Table 9. EDE transient and chronic poverty measures 1996-2010; $\alpha=2 ; \mathrm{t}=3$

\begin{tabular}{|c|c|c|c|c|c|c|}
\hline \multirow{3}{*}{ Components } & \multicolumn{2}{|c|}{ Without bias corrections } & \multicolumn{4}{|c|}{ With bias corrections } \\
\hline & \multirow{2}{*}{$\begin{array}{l}\text { Lower } \\
\text { bound }\end{array}$} & \multirow{2}{*}{$\begin{array}{l}\text { Upper } \\
\text { bound }\end{array}$} & \multicolumn{2}{|c|}{ Lower bound } & \multicolumn{2}{|c|}{ Upper bound } \\
\hline & & & Analytical & Bootstrap & Analytical & Bootstrap \\
\hline \multirow[t]{2}{*}{ Average gap $\zeta_{1}\left(\lambda_{\alpha}\right)$} & 0.355 & 0.269 & 0.355 & 0.355 & 0.269 & 0.252 \\
\hline & $(0.001)$ & $(0.002)$ & $(0.001)$ & $(0.001)$ & $(0.002)$ & $(0.002)$ \\
\hline \multirow{2}{*}{ Cost of inequality $\emptyset_{\alpha}\left(\lambda_{\alpha}\right)$} & 0.000 & 0.053 & 0.000 & -0.094 & 0.034 & 0.031 \\
\hline & $(0.000)$ & $(0.001)$ & $(0.000)$ & $(0.000)$ & $(0.001)$ & $(0.001)$ \\
\hline \multirow[t]{2}{*}{ Transient $\zeta^{*}(\lambda)$} & 0.230 & 0.065 & 0.298 & 0.324 & 0.085 & 0.087 \\
\hline & $(0.001)$ & $(0.001)$ & $(0.001)$ & $(0.001)$ & $(0.001)$ & $(0.001)$ \\
\hline \multirow[t]{2}{*}{ Chronic $\eta_{\alpha}(\mathrm{g})$} & 0.355 & 0.322 & 0.286 & 0.261 & 0.303 & 0.300 \\
\hline & $(0.001)$ & $(0.002)$ & $(0.001)$ & $(0.001)$ & $(0.002)$ & $(0.002)$ \\
\hline \multirow[t]{2}{*}{ Total poverty $\zeta_{\alpha}(\lambda)$} & 0.585 & 0.388 & 0.585 & 0.585 & 0.388 & 0.388 \\
\hline & $(0.000)$ & $(0.002)$ & $(0.001)$ & $(0.000)$ & $(0.002)$ & $(0.002)$ \\
\hline
\end{tabular}

Source: Author's computation based on household surveys of Nigeria 
Note: “The terms 'Upper' and 'Lower' bounds do not refer to within a range but to estimates obtained from predicted consumptions using lower and upper bounds non-parametric approaches. Hence, the 'Lower' estimate for a type can happen to exceed the corresponding 'Upper' estimate."

\subsection{Determinants of poverty entries and exits}

Given the nature of my dataset (in that I do not have actual panel but repeated crosssections), the results discussed here are based on two sets of constructed synthetic panels: (i) 1980, 1985, and 1992; and (ii) 1996, 2004, and 2010. It should be noted, however, that the households in set (i) are not the same households as in set (ii), although both sets are drawn from the same population across time. This was necessary because the non-parametric synthetic panel methodology used to construct the panels, based on the literature (see Dang et al., 2014), allow the construction of a maximum of a three-period panel.

A censored-type model has been used to estimate the specified models. This is due to the nature of outcome variables (transient and chronic poverty), as the value of zero is assigned to any observation (or household) in the sample found to have no poverty experience, i.e., with per capita expenditure above the poverty line in all observed periods for which data is available. For the period in (i), after applying the procedure for constructing synthetic panel, the final sample size is 6,717 . Of this number, using the $\$ 1.25$ per person per day poverty line, there are 1,294 chronically poor and 5,133 transiently poor households in the sample. The other observations are censored. More observations were censored when estimating chronic poverty model than they were when estimating transient poverty. On the other hand, the second set of the synthetic panel in (ii) has a total final sample size of 11,813 households. Using the same poverty threshold, 6,227 and 11,611 of the observations are deemed to be chronically and transiently poor respectively.

Table 10 shows the regression coefficients of the models, for determinants of chronic and transient poverty over 1980-92. The same set of covariates have been controlled for in both the chronic and transient poverty regressions. As can be seen from the Pseudo $\mathrm{R}^{2}$ values, the controls explain chronic poverty better than transient poverty. The model also suggests that household size is the most important determinant of both transient and chronic poverty as the size of the coefficient, relative to those of other controls, is bigger as both components of poverty are found to be increasing functions of household size. But the household size seems to be a more important determinant of chronic poverty than transient poverty.

The table shows in column 1 that, although not statistically significantly different, chronic poverty tends to rise with age of household head. However, the corresponding result, (i.e., coefficient of age in the transient poverty regression in column 2), is significant at 1 percent. In the specifications, the presence of a non-linear relationship between age and poverty is assumed.

To accurately model or account for this effect, the square of "age of household head" is added. It is found that, the coefficient of age (irrespective of the type of poverty) is positive while that of age squared is negative. This means there is some evidence of life-cycle effect in the relationship in that both chronic and transient poverty rise with age up until a peak, 
and then starts to fall with it. This is quite the opposite of what most studies report (e.g. Ravallion, 1998) and what is found in the literature of labour economics regarding the relationship between age and wage. This is fairly a difficult case to interpret. However, the likely plausible interpretation could be linked to old age security. It is typical in developing countries for parents to view their children as means for ensuring security in old age. This contributes to the demand for large families. It may be the case that children from poor families who are fortunate enough to attain some level of education or acquire incomegenerating skills are able to financially support their parents to break free from poverty.

Table 10. Poverty regressions (determinants of chronic and transient poverty), 1980-92

\begin{tabular}{llccc}
\hline \multirow{2}{*}{ Variable } & \multicolumn{2}{c}{$\begin{array}{c}\text { Chronic poverty }\left(\delta^{C}\right) \\
\text { Transient poverty } \\
\end{array}$} & \multicolumn{2}{c}{$\left(\delta^{T}\right)$} \\
\cline { 2 - 5 } & \multicolumn{1}{c}{ Coef } & t-stat & Coef & t-stat \\
\hline Age of household head & 0.002 & 0.158 & $0.0071^{* *}$ & 2.906 \\
Household size & $0.100^{* *}$ & 9.983 & $0.0467^{* *}$ & 4.868 \\
Age of household head squared & -0.00005 & -0.340 & $-0.0001^{* *}$ & -2.819 \\
Household size squared & $-0.002^{* *}$ & -6.165 & $-0.0024^{* *}$ & -3.186 \\
Years of schooling of household head & $-0.011^{* *}$ & -3.574 & $-0.0017^{* *}$ & -3.523 \\
Farming as occupation of head (dummy) & -0.002 & -0.158 & 0.0053 & 1.641 \\
Household living in oil state (dummy) & -0.022 & -0.951 & $-0.0192^{* *}$ & -2.660 \\
Household head is male (dummy) & $-0.070^{* *}$ & -4.090 & $-0.0250^{* *}$ & -3.601 \\
Household living in urban area (dummy) & $-0.047^{* *}$ & -2.860 & -0.0031 & -0.892 \\
Head has primary education (dummy) & 0.001 & 0.027 & 0.0050 & 1.112 \\
Head has Secondary education (dummy) & 0.026 & 0.602 & 0.0032 & 0.347 \\
Living in South-West region (dummy) & 0.019 & 0.487 & -0.0006 & -0.083 \\
Living in North-Central region (dummy) & $0.050^{*}$ & 2.239 & $0.0123^{*}$ & 2.197 \\
Living in North-East region (dummy) & 0.037 & 1.680 & 0.0110 & 1.762 \\
Living in North-West region (dummy) & 0.026 & 1.235 & 0.0103 & 1.841 \\
\hline Pseudo R ${ }^{2}$ & & 0.199 & & 0.081 \\
Observations & & 1,294 & & 5,133 \\
\hline
\end{tabular}

Notes: ${ }^{*}$ Indicates significance at $5 \% ;{ }^{* *}$ Indicates significance at $1 \%$;

Source: Author's computation using household surveys of Nigeria

There are signs that education, measured by years of schooling, reduces the extent of both chronic poverty and transient poverty, as both coefficients are found to be significant at 1 percent. However, the sizes of these coefficients differ in terms of the extents of their impacts. The coefficient for education is more chronic poverty-reducing than its transient counterpart. This result is consistent with Ravallion and Chen's (1988, 1998, 2000). These authors, based on empirical findings using China rural data, conclude that chronic poverty is better addressed (or escaped) through investing in and improving the returns to human capital of the chronically poor. 
Table 11. Poverty regressions, initial poverty line raised by $50 \%$

\begin{tabular}{|c|c|c|c|c|}
\hline \multirow[t]{2}{*}{ Variable } & \multicolumn{2}{|c|}{$\begin{array}{c}\text { (1) } \\
\text { Chronic poverty } \\
\left(\delta^{C}\right)\end{array}$} & \multicolumn{2}{|c|}{$\begin{array}{c}(2) \\
\text { Transient poverty } \\
\left(\delta^{T}\right)\end{array}$} \\
\hline & Coef & t-stat & Coef & t-stat \\
\hline Age of household head & 0.00170 & 0.230 & 0.0014334 & 0.519 \\
\hline Household size & $0.10232 * *$ & 16.495 & $0.0413648^{*}$ & 2.550 \\
\hline Age of household head squared & -0.00004 & -0.414 & -0.0000148 & -0.397 \\
\hline Household size squared & $-0.00236^{* *}$ & -8.874 & $-0.0035289 *$ & -2.288 \\
\hline Years of schooling of household head & $-0.00911^{* *}$ & -3.597 & -0.0005651 & -0.901 \\
\hline Farming as occupation of head (dummy) & 0.01183 & 1.203 & 0.0047956 & 1.361 \\
\hline Household living in oil region (dummy) & -0.02135 & -1.123 & -0.0032767 & -0.709 \\
\hline Household head is male (dummy) & $-0.05684 * *$ & -4.292 & $-0.0111814^{*}$ & -2.601 \\
\hline Household living in urban area (dummy) & $-0.03880^{* *}$ & -3.754 & 0.0034942 & 1.094 \\
\hline Head has primary education (dummy) & 0.01382 & 0.742 & -0.00053 & -0.116 \\
\hline Head has Secondary education (dummy) & 0.01887 & 0.626 & -0.0043031 & -0.507 \\
\hline Living in South-West region (dummy) & 0.00794 & 0.338 & 0.009667 & 1.669 \\
\hline Living in North-Central region (dummy) & 0.02342 & 1.440 & $0.016867 * *$ & 3.071 \\
\hline Living in North-East region (dummy) & $0.03794^{*}$ & 2.248 & $0.0127434^{*}$ & 2.565 \\
\hline Living in North-West region (dummy) & 0.02692 & 1.816 & 0.0089516 & 1.851 \\
\hline Pseudo $\mathrm{R}^{2}$ & 0.257 & & 0.050 & \\
\hline Observations & 3,063 & & 5,619 & \\
\hline
\end{tabular}

Notes: *Indicates significance at $5 \%$; **Indicates significance at $1 \%$;

Source: Author's computation using household surveys of Nigeria

A dummy is included for whether farming is the major occupational activity of the household head. Although, the coefficient is not significant, the signs for both components of poverty are not the same. Households that farm are more likely to be transient poor (the sign of the coefficient is positive) than chronic poor (the coefficient is negative). It is likely the case that given the predominance of agriculture as a major occupation of the poor, weather and price unpredictability are deemed to have, in large part, fueled fluctuations in income of the poor. This is coupled with the fact that in most developing countries, including Nigeria, robust social insurance institutions for smoothing consumption in periods of bad shocks, are lacking (Deaton, 1992). The coefficient of the dummy for households living in oil-producing states (the South-South region), is found to be negative for both types of poverty. This is significant for transient poverty but not for chronic poverty. The message emerging from this is that those living in this region are more disposed to transient poverty than to chronic poverty. 
My results show that there is heterogeneity across gender in the determinants of poverty. The dummy-coefficient for male-headed households is negative and not different from zero (at 1 percent) for both chronic and transient poverty. But the coefficient for chronic poverty is larger (as is the t-statistic) than the coefficient for transient poverty. This implies that female-headed households are more chronic poverty-stricken than their male-headed counterparts. In other words, they tend to experience poverty more ceaselessly than their male equals. Coefficient of the dummy for household living in urban area is negative and significant for chronic poverty; negative but not significant for transient poverty. Relative to rural residents, urban population is less likely to be in transient and chronic poverty. Contrasting with the Southeast region (the base category), dummies for living in Southwest, Northeast, and Northwest regions of the country are found not be significant at the chosen levels of significance, 1 percent and 10 percent.

Given the high degree of censoring arising from estimating the chronic poverty regression $(5,423$ households, or about 81 percent of the total sample size from the panel were censored), concern arises over the robustness of estimates presented in Table 10; the estimates were obtained from a relatively small sample. Since the poverty rate is an increasing function of a poverty line that is somewhat arbitrarily chosen, Ravallion (1998) proposed raising the poverty threshold by some amount as a way of dealing with this concern. In the spirit of these authors, for my analysis I raised the US $\$ 1.25$ poverty line by 50 percent to US $\$ 1.875$ per person per day. Applying this inflated line, Table 11 shows that the number of the chronically poor from my total sample size of 6,717 households increased from 1,294 to 3,063 households. Contrasting with the results in Table 2.10, as would be expected, the Pseudo $\mathrm{R}^{2}$ values for both chronic poverty and transient poverty, as well as their respective t-statistic rose. However, the signs of all the coefficients remained unchanged except a few from the transient poverty regression, which became less significant. One can therefore conclude that augmenting the sample size using a higher poverty threshold offers no significant difference to the interpretation of the results in Table 10 and Table 3.10-the changes in methodology did not produce big changes in my results. Table 12 shows the corresponding regressions for Table 10 for the period 1996-2010. The results in both tables applied the same set of controls and outcome variables. The results show that both transient poverty and chronic poverty have deepened overtime. In Table 10, about 19 percent of households in the sample have experienced chronic poverty. This percentage rose to 53 percent over the 1996-2010 period. Further, in Table 10, the dummy-coefficient for households into farming obtained from the chronic (transient) poverty regression was found to be negative (positive) and at the same time statistically insignificant. 
Table 12. Poverty regressions, 1996-2010

\begin{tabular}{|c|c|c|c|c|}
\hline \multirow[t]{2}{*}{ Variable } & \multicolumn{2}{|c|}{$\begin{array}{c}\text { (2) } \\
\text { Chronic poverty } \\
\left(\delta^{T}\right)\end{array}$} & \multicolumn{2}{|c|}{$\begin{array}{c}(3) \\
\text { Transient poverty } \\
\left(\delta^{C}\right)\end{array}$} \\
\hline & Coef & t-stat & Coef & t-stat \\
\hline Age of household head & 0.00336 & 0.709 & 0.000298 & 0.238 \\
\hline Household size & $0.08693 * *$ & 15.556 & $0.018446 * *$ & 18.795 \\
\hline Age of household head squared & -0.00004 & -0.776 & -0.000004 & -0.272 \\
\hline Household size squared & $-0.00397 * *$ & -12.754 & $-0.001008^{* *}$ & -12.229 \\
\hline Years of schooling of household head & $-0.00492 * *$ & -4.993 & -0.000268 & -1.288 \\
\hline Farming as occupation of head (dummy) & $0.03121 * *$ & 4.116 & -0.0028 & -1.512 \\
\hline Household living in oil state (dummy) & $-0.05918^{* *}$ & -4.695 & $-0.007451 * *$ & -3.092 \\
\hline Household head is male (dummy) & $-0.03022 *$ & -2.116 & $-0.008225^{* *}$ & -3.108 \\
\hline Household living in urban area (dummy) & $-0.07801 * *$ & -6.334 & -0.003187 & -1.805 \\
\hline Head has primary education (dummy) & 0.00180 & 0.158 & 0.002434 & 0.913 \\
\hline Head has Secondary education (dummy) & 0.00546 & 0.623 & -0.001127 & -0.470 \\
\hline Living in South-West region (dummy) & $-0.04773 *$ & -2.461 & $0.004717 *$ & 2.097 \\
\hline Living in North-Central region (dummy) & 0.02013 & 1.888 & $0.011908^{* *}$ & 4.772 \\
\hline Living in North-East region (dummy) & $0.02469 *$ & 2.258 & 0.003510 & 1.494 \\
\hline Living in North-West region (dummy) & $0.03141 * *$ & 3.205 & 0.001886 & 0.905 \\
\hline Constant & $-0.24606^{*}$ & -2.444 & -0.014268 & -0.596 \\
\hline Pseudo R2 & \multicolumn{2}{|c|}{0.094} & \multicolumn{2}{|c|}{0.035} \\
\hline Observations & \multicolumn{2}{|c|}{6,227} & \multicolumn{2}{|c|}{11,611} \\
\hline
\end{tabular}

Notes: $*$ Indicates significance at $5 \% ;{ }^{* *}$ Indicates significance at $1 \%$

Source: Author's computation using household surveys of Nigeria, 1996, 2004 and 2010

However, I found this to be the opposite of the results presented in Table 12 (1996-2010). The coefficients switched signs. Chronic (Transient) poverty's became positive (negative); but the significant level of transient's remained unchanged, and still insignificant. The inference from this is that, over time, the proportion of chronically (or transiently) poor households that are into farming has risen (declined).

Another difference between the results in Table 10 (or Table 11 and Table 12) is that, living in oil producing state during 1980-92 period, was found be an insignificant determinant of transient poverty at that time, but has now become a significant determinant of transient poverty, as the estimated corresponding parameter associated with the dummy for the 19962010 period (Table 11), is found to be significant at 1 percent. In a nutshell, poor households living in the oil producing states (Akwai-ibom, Bayelsa, Cross-River, Delta, Edo, and Rivers) have over time become more transiently poor than they were. Further, the coefficients of age (and of age squared) of household heads and of the years of schooling were not significant in my 1980-92 poverty regression results in Table 10 (or Table 11). In the 19962010 results (Table 11), their signs remain unchanged, but their degrees of significance have 
improved. The message here is that these variables have become stronger predictors of both transient poverty and chronic poverty than they were over three decades ago. Factors accounting for this divergence cannot be readily verified. The overall patterns in Table 10 (or Table 11) and Table 12 remain unchanged: with the controls being stronger predictors of chronic poverty than transient poverty, implying that the determinants of the two components of poverty are not harmonious.

\section{Conclusion}

The paper shows that a static poverty estimate drawn from independent cross surveys tends to understate the extent of poverty as it is unable to provide information on individual poverty experiences across time and space. The paper explored six sweeps of household surveys of Nigeria (1980-2010) in an attempt to show this. For instance, it is found that between 1980 and 1985, about 0.11 percent to 9.5 percent of the population escaped poverty, but at the same time, more than this fraction moved into poverty: 21.94 percent to 32.27 percent. Further evidence suggests that both transient and chronic poverty were higher in 1996-2010 than in the previous 1980-1992 period. But transient poverty rose faster as the share of chronic poverty in total poverty declined to between 3 percent to 55 percent from about 90 percent. Chronic poverty is less prevalent in Nigeria's oil producing region and more prevalent in the country's northeast. Also, poverty is found to increase with household size. About 81 percent of those trapped in poverty farm and 81.02 percent are from the north.

Years of schooling is found to have the strongest negative impact on chronic poverty. Seventy-four percent of those never trapped in poverty have more than a high school level of education. Stepping up girls' education can mitigate teenage pregnancies and consequently address population rise among the poor. In addition, increasing investment in human capital, through government spending, can help break the cycle of poverty in the northern region of the country that is found to be more affected by this type of poverty.

Transient poverty is less dependent on household demographics, but often linked to financial development. Financial development that mitigates the impact of vulnerability enables households to increase their expected earnings (Morduch, 1994). The absence of developed institutions in low-income countries creates a lack of adequate access by victims of negative shocks to consumption-smoothing mechanism or facilities. Chronic poverty, on the other hand, is significantly determined by the structural (or intrinsic) demographic characteristics of the poor: household size, age, level of education, location, gender, and so on.

To accurately model or account for this effect, the square of "age of household head" is added. It is found that the coefficient of age (irrespective of the type of poverty) is positive while that of age squared is negative. This means there is some evidence of life-cycle effect in the relationship in that both chronic and transient poverty rise with age up until a peak, and then starts to fall with it. This is quite the opposite of what most studies report (e.g. Ravallion, 1998) and what is found in the literature of labour economics regarding the relationship between age and wage. This is fairly a difficult case to interpret. However, the 
likely plausible interpretation could be linked to old age security. It is typical in developing countries for parents to view their children as means for ensuring security in old age. This contributes to the demand for large families. It may be the case that children from poor families who are fortunate enough to attain some level of education or acquire incomegenerating skills are able to financially support their parents to break free from poverty.

Finally, to test whether different processes are at work in determining the two components of poverty. I do so by estimating poverty regressions using a censored conditional quantile estimation method, a method considered to be robust in the presence of misspecifications in the error distribution. These exercises are essential in that maximizing progress against poverty requires understanding the type of poverty at issue and its determinants; different policies are called for when addressing these two types of poverty.

My results do not support the claim that the same set of household demographics equally determines chronic and transient poverty. The call, therefore, for strategies to deal with these components of poverty should be heterogeneous across the poor. The chronically poor suffer for lack of earning capacity. Education or other forms of skills training programmes (some form of human capital development) may create or boost their earning capacity, and, as noted by Morduch (1994), transient poverty in low-income countries is often a result of a failure to find protection against stochastic elements in the economic environment.Strengthening social protection provisions can enable households to take risks that raise their expected incomes. For instance, the oil producing region is more transientpoverty stricken than other regions in the country. The policy implication is that, approach to dealing with poverty in this region should differ from the North's where chronic poverty is dominant. Also, raising investment in human capital will be more effective in fighting poverty in the north than in the oil-producing region. 


\section{References}

Andriopoulou, E., \& Tsakloglou, P. (2011). The determinants of poverty transitions in Europe and the role of duration dependence.

Anyanwu, John C. (2005). Rural poverty in Nigeria: Profile, determinants and exit paths. African Development Review, 17(3), 455-460.

Antman, F., \& McKenzie, D. (2007). Earnings Mobility and Measurement Error: A PseudoPanel Approach. Economic Development and Cultural Change, 56(1), 125-161.

Simon Appleton, Andrew McKay and Babatunde Adewunmi Alayande (2008). Poverty in Nigeria. In: Collier, P., Soludo, C. C., \& Pattillo, C. A. (Eds.). (2008). Economic policy options for a prosperous Nigeria. New York, NY: Palgrave Macmillan.

Appleton, S. (2001). Education, Incomes and Poverty in Uganda in the 1990s. (No. 01/22). University of Nottingham.

Atkinson, A. B. (1970). On the measurement of inequality. Journal of economic theory, 2(3), 244-263.

Bane, M. J., \& Ellwood, D. T. (1986). Slipping into and out of Poverty: The Dynamics of Spells. Journal of Human Resources, 21(1), 1-23.

Blundell, R., Duncan, A., \& Meghir, C. (1998). Estimating Labor Supply Responses Using Tax Reforms. Econometrica, 66(4), 827-861.

Bourguignon, F., Goh, C.-c., \& Kim, D. I. (2004). Estimating individual vulnerability to poverty with pseudo-panel data. Policy Research Working Paper Series(3375).

Breen, R., \& Moisio, P. (2004). Poverty dynamics corrected for measurement error. Journal of Economic Inequality, 2(3), 171-191.

Buchinsky, M. (1994). Changes in the US wage structure 1963-1987: Application of quantile regression. Econometrica: Journal of the Econometric Society, 405-458.

Canagarajah, S., \& Thomas, S. (2001). Poverty in a Wealthy Economy: the Case of Nigeria. Journal of African Economies, 10(2), 143-173.

Cappellari, L., \& Jenkins, S. P. (2002). Who Stays Poor? Who Becomes Poor? Evidence from the British Household Panel Survey. The Economic Journal, 112(478), C60-C67.

Cruces, G., Viollaz, M., Lanjouw, P., Lucchetti, L., Perova, E., \& Vakis, R. (2014). Estimating poverty transitions using repeated cross- sections: a three-country validation exercise. The Journal of Economic Inequality.

Cruces, G., \& Wodon, Q. (2003). Transient and chronic poverty in turbulent times: Argentina 1995-2002. Economics Bulletin, 9(3), 1-12.

Cuesta, J., Ñopo, H., \& Pizzolitto, G. (2011). Using Pseudo- Panels To Measure Income Mobility In Latin America. Review of Income and Wealth, 57(2), 224-246. doi:10.1111/j.1475-4991.2011.00444.x

Dang, H. A., Lanjouw, P., Luoto, J., \& McKenzie, D. (2014). Using repeated cross- sections to explore movements into and out of poverty. Journal of Development Economics, 107, 112128.

Dang, H. A. H., \& Dabalen, A. L. (2018). Is Poverty in Africa mostly chronic or transient? evidence from synthetic panel data. The Journal of Development Studies, 1-21.

Deaton, A. (1985). Panel data from time series of cross-sections. Journal of Econometrics, 30(12), 109-126. 
Deaton, A. (1997). The analysis of household surveys: a microeconometric approach to development policy: World Bank Publications.

Dercon, S., \& Shapiro, J. S. (2007). Moving on, staying behind, getting lost: Lessons on poverty mobility from longitudinal data. Moving out of Poverty, 1, 77-126.

Duclos, J.-Y., Araar, A., \& Giles, J. (2010). Chronic and transient poverty: Measurement and estimation, with evidence from China. Journal of Development Economics, 91(2), 266-277.

Duncan, G. J., Coe, R., Corcoran, M., Hill, M. S., Hoffman, S., \& Morgan, J. N. (1984). Years of poverty--years of plenty: The changing economic fortunes of American workers and families.

Elbers, C., Lanjouw, J. O., \& Lanjouw, P. (2002). Micro-level estimation of welfare (Vol. 2911). World Bank Publications.

FOS, (1999). Poverty Profile for Nigeria: a Statistical Analysis of 1996/97 National Consumer Survey (with reference to1980, 1985,92). Retrieved from Lagos:

https://uk.search.yahoo.com/search/?p=Status + of + Women $\% 3 \mathrm{~A}+$ Indicators + for + Tw enty-five + Countries\&ei $=U T F-8 \&$ fr $=$ spigot-chr-ffmac\&type $=216107 \&$ ilc $=12$

Haughton, J., \& Khandker, S. R. (2009). Handbook on Poverty and Inequality. World Bank Publications.

Hulme, D., \& Shepherd, A. (2003). Conceptualizing chronic poverty. World Development, 31(3), 403-423.

Jalan, J., \& Ravallion, M. (1998). Transient Poverty in Postreform Rural China. Journal of Comparative Economics, 26(2), 338-357.

Jalan, J., \& Ravallion, M. (2000). Is transient poverty different? Evidence for rural China. Journal of Development Studies, 36(6), 82-99.

Jarvis, S., \& Jenkins, S. P. (1995). Do the poor stay poor? new evidence about income dynamics from the British Household Panel Survey: ESRC Research Centre on Micro-Social Change.

Jenkins, Stephen P. (2011). Changing fortunes : income mobility and poverty dynamics in Britain. Oxford: Oxford : Oxford University Press.

Langeheine, R., Rendtel, U., \& Berntsen, R. (1998). The estimation of poverty dynamics using different measurements of household income. Review of Income and Wealth, 44(1), 81-98.

Middleton, N. S. a. S. (2007). A review of poverty dynamics research in the UK. In: Joseph Rowntree Foundation.

Morduch, J. (1994). Poverty and Vulnerability. The American Economic Review, 84(2), 221-225.

Moffitt, Robert. (1993). Identification and estimation of dynamic models with a time series of repeated cross-sections. Journal of Econometrics, 59(1-2), 99-123.

Mukherjee, S., \& Benson, T. (2003). The determinants of poverty in Malawi, 1998. World Development, 31(2), 339-358.

NBS, (2012). Nigerian Poverty Profile, 2010. Retrieved from Abuja, Nigeria:

Nijman, T., \& Verbeek, M. (1992). Nonresponse in panel data: The impact on estimates of a life cycle consumption function. Journal of Applied Econometrics, 7(3), 243-257.

Ravallion, M. (1995). Growth and poverty: Evidence for developing countries in the 1980s. Economics letters, 48(3-4), 411-417.

Shaw, A., Great Britain. Department of Social, S., \& Centre for Research in Social, P. (1996). Moving off income support: barriers and bridges : a survey carried out on behalf of the Department of Social Security by the Centre for Research in Social Policy, Loughborough University. 
Stevens, A. H. (1994). The dynamics of poverty spells: Updating Bane and Ellwood. The American Economic Review, 84(2), 34-37.

Sudharshan Canagarajah, \& Thomas, Saji. (2001). Poverty in a Wealthy Economy: the Case of Nigeria. Journal of African Economies, 10(2), 143-173.

Walker J. and Park, Reed (1998). "Unpicking Poverty" in: An Inclusive Society. (Oppenheim, C. ed.) IPPR, London.

Woolard, I., \& Klasen, S. (2005). Determinants of income mobility and household poverty dynamics in South Africa. Journal of Development Studies, 41(5), 865-897. 


\section{Appendix}

\section{Meeting the data requirement: construction of synthetic panel}

The household survey in Nigeria is not a panel dataset in that it does not follow the same individual households through time. However, the survey is carried out frequently and provides information on a random sample of the population each year. Over the past three decades, reports on poverty incidences in Nigeria by the NBS were derived from the independent random survey series of ICS, which is carried out every 5 years. Over the period 1980-2010 there were six such surveys. However, since there is no way of linking households across ICS, such reports only provide static poverty and inequality profiles. In other words, they depict the extent of poverty and inequality only at a given point in time and conditional on household characteristics.

The recent methodological developments provide us with different synthetic-panel techniques, known as cohort-mean-based and dispersion-based techniques, for analyzing mobility and estimating panel models using repeated cross-sectional surveys. These techniques vary in their data requirements and assumptions about structural parameters, and in the mobility question they attempt to answer. The methodology requires that two conditions be satisfied. First, the underlying population sampled must be the same in both rounds and must have similar household characteristics. This condition provides an essential linkage between household consumptions in both periods. The condition will not be satisfied if the underlying population changes through births, deaths, or migration out of sample, sudden economic crisis, net inequality, etc., which is more likely if the time distance between the two surveys is sufficiently long.

Second, the correlation between the two innovation terms, $\varepsilon_{i 1}$ and $\varepsilon_{i 2}$, is to be positive otherwise households will have lower consumption than their $x_{i j}$ ( $j$ represents a given round) would predict in round 1 , and higher consumption than would be predicted for round 2 . The probability of this condition being breached, for the majority of households simultaneously, is significantly low. ${ }^{3}$ Since the dataset available to us is cross-section, thus, we do not know $y_{i 1}$ and $y_{i 2}$ for the same households. One way to address this problem is to derive bounds. Rewriting the probability in (3.1), we have:

$$
p\left(\varepsilon_{i 1}<z_{1}-\hat{\beta}_{1} x_{i 2} \text { and } \varepsilon_{i 2}<z_{2}-\hat{\beta}_{2} x_{i 2}\right)(7.33)
$$

The intuition is that, the probability in (7.1) depends on the joint distribution of $\varepsilon_{i 1}$ and $\varepsilon_{i 2}$, i.e the correlation between unexplained (not explained by household characteristics) determinants of consumptions (or income) in rounds 1 and $2, \rho$. It follows therefore that mobility will be greater, the higher the value of $\rho$. This means, household consumption in period 1 will be highly associated with household consumption in period 2 . However, $\rho$ can

\footnotetext{
${ }^{3}$ See Dang et al. (2014) for details on how this was proved using panel datasets.
} 
also assume extreme values: 0 and 1, respectively, when they are completely orthogonal (or independent of each other) and when they are perfectly correlated. In the spirit of Dang et al., 2014, I therefore assume that the error terms are positive quadrant dependent:

$p\left(\varepsilon_{i 1}<z_{1}-\hat{\beta}_{1} x_{i 2}\right.$ and $\left.\varepsilon_{i 2}<z_{2}-\hat{\beta}_{2} x_{i 2}\right) \geq P\left(\varepsilon_{i 1}<z_{1}-\hat{\beta}_{1} x_{i 2}\right) P\left(\varepsilon_{i 2}<z_{2}-\hat{\beta}_{2} x_{i 2}\right)$

Or:

$P\left(\varepsilon_{i 1}<z_{1}-\hat{\beta}_{1} x_{i 2}\right.$ and $\left.\varepsilon_{i 2}<z_{2}-\hat{\beta}_{2} x_{i 2}\right) \geq P\left(\varepsilon_{i 1}<z_{1}-\hat{\beta}_{1} x_{i 2}\right) P\left(\varepsilon_{i 2}<z_{2}-\hat{\beta}_{2} x_{i 2}\right)$

We now follow the procedure for estimating the unobserved consumptions. To proceed, let $x_{i 1}$ and $x_{i 2}$ represent control vectors, i.e., demographics for household consumptions in rounds 1 and 2 respectively. It is required that these controls be the same in both rounds. Consequently, the estimate of round 1 consumption regressions is:

$$
y_{i 1}=\beta_{1} x_{i 1}+\varepsilon_{i 1} \quad i=1,2, \ldots, n_{1}
$$

Similarly, the linear projection of round 2 consumption $y_{i 2}$, onto $x_{i 2}$ is given by:

$$
y_{i 2}=\beta_{2} x_{i 2}+\varepsilon_{i 2}, \quad i=1,2, \ldots, n_{2}
$$

$\varepsilon_{i 1}$ and $\varepsilon_{i 2}$ are respectively the unobserved determinants of consumptions in the first and second rounds, where

$$
\hat{\varepsilon}_{i 1}=y_{i 1}-\hat{\beta}_{1} x_{i 1}, \quad i=1, \ldots, n_{1}
$$

and

$$
\hat{\varepsilon}_{i 2}=y_{i 2}-\hat{\beta}_{2} x_{i 2}, \quad i=1, \ldots, n_{2} .
$$

Since we do not have actual panel, $y_{i 1}$ is not observed but $y_{i 2}$ is. And in the case the $y_{i 1}$ is observed, then $y_{i 2}$ is not. Dang et al. (2014) proposed a non-parametric methodology in dealing with this (estimating $y_{\mathrm{i} 1}$ ) in two ways as follows, I now take random drawing of (7.5) 
with replacement and denote by $\breve{\varepsilon}_{i 1}$, which is then used in (7.7) for estimating upper bound consumption: ${ }^{4}$

$$
\breve{y}_{i 1}^{2 U}=\hat{\beta}_{1} x_{i 2}+\breve{\varepsilon}_{i 1}, \quad i=1, \ldots, n_{2}
$$

To obtain the lower bound consumption, I introduced $\hat{\lambda}$ into (7.7); and replacing $\breve{\varepsilon}_{i 1}$ with $\hat{\varepsilon}_{i 2}$ we have:

$$
\breve{y}_{i 1}^{2 L}=\hat{\beta}_{1} x_{i 2}+\hat{\lambda} \hat{\varepsilon}_{i 2}, \quad i=1, \ldots, n_{2},
$$

where, $\hat{\lambda}=\frac{\widehat{\sigma}_{\varepsilon 2}}{\widehat{\sigma}_{\varepsilon 1}} \cdot \hat{\lambda}$ is introduced because the predicted consumption for the lower bound is based on the assumption of perfect positive covariance between the two error terms. ${ }^{5}$

Where, $\breve{y}_{i 1}$ denotes estimated round 1 household PCE, the superscripts $2 U$ stands for upper bound estimated round 1 consumption for households surveyed in round 2 , and $2 L$ stands for the lower bound estimated round 1 consumption for households surveyed in round 2. $\hat{\beta}_{1}$ is a vector of estimated parameters obtained from round 1 consumption regression; $x_{i 2}$ is a set of time-invariant controls in round 2 ; $\hat{\varepsilon}_{i 2}$ is the estimated round 2 error term; $\breve{\varepsilon}_{i 1}$ is a random draw with replacement of $\hat{\varepsilon}_{i 2}$; and $\frac{\widehat{\sigma}_{\varepsilon 1}}{\widehat{\sigma}_{\varepsilon 2}}$ is the ratio of estimated round 1 variance to round 2's from respective consumption regressions. ${ }^{6}$

The result of this method producing lower and upper bound estimates of consumptions is the product of upper and lower bound of estimates of poverty mobility. It is expected that the unobserved true mobility rates from actual panel datasets are embedded between the lower and upper bounds rates.

\section{Extending beyond two rounds}

To analyses changes in welfare beyond these periods, I now generalize this method to a setting where there are three rounds of survey. I do this by estimating rounds 1 and 3 using the households consumptions surveyed in round 2. Consequently, I am interested in knowing such quantities as:

\footnotetext{
${ }^{4}$ The superscripts attached to the consumption variables denote the survey rounds to which they belong i.e. 1 for round 1 and 2 for round 2 .

${ }^{5}$ Since $\operatorname{Cor}\left(\varepsilon_{i 1}, \varepsilon_{i 2}\right)=\frac{\operatorname{cov}\left(\varepsilon_{i 1}, \varepsilon_{i 2}\right)}{\sqrt{\widehat{\sigma}_{\varepsilon 1}^{2} \widehat{\sigma}_{\varepsilon 2}^{2}}}=1$, we have $\operatorname{cov}\left(\varepsilon_{i 1}, \varepsilon_{i 2}\right)=\sqrt{\hat{\sigma}_{\varepsilon 1}^{2} \hat{\sigma}_{\varepsilon 2}^{2}}$, then it follows that $\hat{\lambda}=$

$\operatorname{cov}\left(\varepsilon_{i 1}, \varepsilon_{i 2}\right) /\left(\hat{\sigma}_{\varepsilon 2}^{2}\right)=\hat{\sigma}_{\varepsilon 1} / \hat{\sigma}_{\varepsilon 2}$

${ }^{6}$ Regression results are reported in Error! Reference source not found.
} 


$$
\begin{gathered}
y_{i 1}<z ; y_{i 2}<z \text { and } y_{i 3}<z \\
y_{i 1}<z ; y_{i 2}<z \text { and } y_{i 3}>z \\
y_{i 1}<z ; y_{i 2}>z \text { and } y_{i 3}>z \\
y_{i 1}<z ; y_{i 2}>z \text { and } y_{i 3}<z \\
y_{i 1}>z ; y_{i 2}>z \text { and } y_{i 3}<z \\
y_{i 1}>z ; y_{i 2}<z \text { and } y_{i 3}<z \\
y_{i 1}>z ; y_{i 2}>z \text { and } y_{i 3}>z
\end{gathered}
$$

and

$$
p\left(\mathrm{y}_{\mathrm{i} 1} \sim \mathrm{z} \text { and } \mathrm{y}_{\mathrm{i} 2} \sim \mathrm{z}, \mathrm{y}_{\mathrm{i} 3} \sim \mathrm{z}\right)
$$

is a compact version of (7.9)- (7.15), where, " " is either ">", "<", " $\geq$ " or " $\leq$ "as relevant.

Since I have, as show above, explained how round 1 (past consumption) was predicted, I now estimate $y_{i 3}$, unobserved upper bound round 3 consumptions, as follows:

$$
\breve{y}_{i 3}^{2 U}=\hat{\beta}_{3} x_{i 2}+\breve{\varepsilon}_{i 3}, i=1, \ldots, n_{2}
$$

and the lower bound:

$$
\breve{y}_{i 3}^{2 L}=\hat{\beta}_{3} x_{i 2}+\frac{\widehat{\sigma}_{\varepsilon 3}}{\widehat{\sigma}_{\varepsilon 2}} \hat{\varepsilon}_{i 2}, i=1, \ldots, n_{2}
$$

$\hat{\beta}_{3}$ is vector of estimated parameters from round 3 cross-section and $\breve{\varepsilon}_{i 3}$ is a random draw of $\hat{\varepsilon}_{i 3}$ which was also estimated from round 3 cross-section consumption regression. I now have rounds 1, 2 and 3 consumptions for the same households, i.e respectively $\breve{y}_{i 1}^{2 U}$ (or $\breve{y}_{i 1}^{2 L}$ ), $y_{i 2 \text {, and }} \breve{y}_{i 3}^{2 U}$ (or $\breve{y}_{i 3}^{2 L}$ ). With these, we can also estimate chronic and transient poverty measures for at least three periods. We show this in the next section.

However, building on Bourguignon, Goh and Kim (2004), Cuesta et al. (2011), and Dang et al. (2014) have proposed a methodology that allows for the creation of a synthetic panel by predicting future or past household consumption using a set of simple modeling and error structure assumptions the paper by Cruces et al (2015) does not proposed a new method, but mostly validate the synthetic panel method developed by Dang et al (2014). This 
enhanced approach allows the estimation of the quantities of poverty transitions between two survey periods. ${ }^{7}$

Synthetic panels are primarily constructed as a response to absence of panel data, and it is not necessarily the case that they will lead to lower quality results. Cruces et al. (2014) apply the synthetic panel in the study of poverty mobility with some modifications: they estimated lower and upper bounds of poverty mobility for Vietnam and Indonesia. They validate their estimates by using both cross sectional and actual panel survey datasets of the same countries. They find that the synthetic panel estimates are close to, and mostly within the 95 percent confidence intervals (or even one standard error interval in many cases), of the actual panel data.

There are a number of advantages associated with synthetic panels over actual panels: (i) there is no non-random attrition problem with synthetic panel because individuals or households are randomly sampled; (ii) synthetic panels suffer less from problems related to measurement error at the individual or household level because they follow cohort means; and (iii) large sample sizes from cross-section surveys allow the construction of synthetic panels covering substantially longer periods than what can be covered by actual panels. However, working with repeated cross-section data is of interest because such data provides a connecting link between micro and aggregate data—see Deaton (1985), Moffit (1993), and Antman and McKenzie (2007) for details.

However, for the above to be achieved, it is suggested that the samples be restricted to households headed by people aged 25 to 55 in the first round and adjusted appropriately in the second round based on the time interval between the surveys. This is based on the fact that analysis of mobility among households headed by those younger than 25 or older than 55 to 60 is more difficult since these ages are often when households are beginning to form or starting to disperse. For Nigeria, I have chosen to restrict the age of household heads from 20 to 45 years in 1980 and then from 25 to 50 in 1985. This range is lower than conventionally prescribed because of the low life expectancy at birth at the time the two surveys were fielded.

\footnotetext{
${ }^{7}$ Since the non-parametric bounds approach has been applied in this study, poverty transition will be estimated on the basis of two adjacent periods, i.e., paring the six cross-sections into three groups.
} 